\title{
ETHNICITY AND CONFLICT: AN EMPIRICAL STUDY
}

\author{
By Joan Esteban, Laura Mayoral and Debraj Ray ${ }^{1}$
}

November 2011

\begin{abstract}
This paper examines the impact of ethnic divisions on conflict. The empirical specification is informed by a theoretical model of conflict (Esteban and Ray, 2011) in which equilibrium conflict intensity is related to just three distributional indices of diversity: ethnic polarization, ethnic fractionalization, and a Greenberg-Gini index of "difference" constructed across ethnic groups. Our empirical findings verify that these distributional measures are significant correlates of conflict. The underlying theory permits us to use these results to make inferences about the relative importance of public goods in conflict, as well as the extent of within-group cohesion in conflictual activity. These effects are further strengthened as we introduce country-specific measures of group cohesion and the relative importance of public goods, and combine them with the distributional measures exactly as specified by the theory.
\end{abstract}

\section{INTRODUCTION}

This paper examines the link between measures of ethnic distribution and social conflict.

The influence of the Marxian paradigm is clearly perceptible in the traditional view that income or wealth inequality is a major potential cause of conflict. Early empirical studies emphasized, accordingly, inequality indicators of personal income or of wealth such

\footnotetext{
${ }^{1}$ Esteban: Institut d'Anàlisi Económica, CSIC and Barcelona GSE; joan.esteban@iae.csic.es. Mayoral: Institut d'Anàlisi Económica, CSIC and Barcelona GSE; laura.mayoral@iae.csic.es. Ray: New York University and Institut d'Anàlisi Económica, CSIC; debraj.ray@nyu.edu. They gratefully acknowledge financial support from CICYT project SEJ-2006-00369. Esteban's research is also funded by the Axa Research Fund. Ray's research was funded by National Science Foundation Grant SES-0962124 and a FulbrightNehru Fellowship from the Fulbright Foundation. He thanks the Indian Statistical Institute for warm hospitality during a year of leave from NYU. We are very grateful to James Fearon for giving us access to his dataset on ethnic groups, to Ignacio Ortuño-Ortín, who computed linguistic indices for us based on the Ethnologue dataset, and to Michael Ross for his dataset on natural resources. We are grateful to Oeindrila Dube, Kaivan Munshi, Natalija Novta and Romain Wacziarg for helpful comments, to Laura Cozma, Andrew Gianou and Bořek Vašíček for superb research assistance, and to seminar participants at various venues where this paper was presented. Finally, we acknowledge the constructive comments made by the Editor and three anonynous referees; the final version owes much to them.
} 
as landownership (see, e.g., Brockett, 1992, Midlarski, 1988, Muller and Seligson, 1987, Muller et al., 1989, and Nagel, 1974, among several others). However, as the survey article by Lichbach (1989) concluded, the empirical results obtained were generally ambiguous, or statistically insignificant.

The emphasis on inequality as a driver of conflict is natural in the sense that the poor might be reasonably expected to harbor strong antagonisms against the rich. Yet the existence of antagonisms is only part of the story. The prevalence of sustained conflict requires those antagonisms to be channeled into organized action, often a tall order when economic strengths are so disparate. The clear economic demarcation across classes is a two-edged sword: while it breeds resentment, the very poverty of the have-nots militates against a successful insurrection, and even then the different skill and occupational niches occupied by capitalist and worker makes effective redistribution across classes a more indirect and difficult prospect.

In contrast, non-economic markers separate individuals that are economically similar. The gains from such conflict are immediate: the losing group can be excluded from the sector in which they directly compete with the winners. ${ }^{2}$ This leads to a different view of social conflict. It could emanate from economic motivations, but find its expression through the cleavages generated by religion, ethnicity, or national origins. It could be further exacerbated by hatreds and resentments - perhaps primordial, perhaps owing to a history of violence - that are attached to the markers themselves. This is why scholars such as Brubaker and Laitin (1998), examining the history of internal conflicts in the second half of the twentieth century, are led to remark on "the eclipse of the left-right ideological axis," and the "marked ethnicization of violent challenger-incumbent contests".

That raises the empirical question: do ethnic divisions matter for conflict? In part, the answer must depend on what is meant by an ethnic "division". A popular candidate is the well-known fractionalization index. It is used as an independent variable in empirical studies on conflict; see, e.g., Collier and Hoeffler (2004), Fearon and Laitin (2003) and

\footnotetext{
${ }^{2}$ In addition, within-group economic disparities allow the complementary activities of conflict funding and conflict participation to take place. Esteban and Ray (2008) base a theory of ethnic salience in conflict on this premise.
} 
Miguel et al. (2004). ${ }^{3}$ But the empirical connection between fractionalization and conflict is missing or at best weak. Fearon and Laitin (2003) conclude that the observed "pattern is thus inconsistent with ... the common expectation that ethnic diversity is a major and direct cause of civil violence."

Of course, there is no reason to expect a connection in the first place, even if we believe that ethnic "divisions" cause conflict. There is no foundation for the assertion that fractionalization captures those divisions. It is a measure taken off the shelf, one that happens to yield the expected results for economic growth or public good provision. An alternative approach is pursued by Montalvo and Reynal-Querol (2005) [MRQ], who conduct the first empirical study relating conflict to ethnic polarization, drawing on the earlier theoretical work of Esteban and Ray $(1994,1999) .{ }^{4}$ Their contribution is important: it provides serious econometric support for the proposition that "deep cleavages" along large group lines might affect conflict. ${ }^{5}$

Our main contention in this paper is that we cannot begin to understand the connections between ethnic divisions and conflict unless we have strong conceptual ground to understand (a) what the relevant notion of a "division" should be, and (b) how such a notion might be sensitive to the underlying nature of the conflict. Theory can and should inform these empirical specifications. As we will argue, a fundamentally important distinction must be drawn between a conflict that is over "public goods" - ideological or religious supremacy, or political power - and one that is over private goods, such as the capture of oil resources or mining revenues. We draw on Esteban and Ray (2011), who develop a theory of conflict across groups with different levels of cohesion, allowing for such "public" and "private" prizes as well as different mixes of those prizes. We review their approach

\footnotetext{
${ }^{3}$ See Blattman and Miguel (2010) for an extensive survey that discuses these and related literature.

${ }^{4}$ Measures of polarization were independently developed by Esteban and Ray (1994) and Wolfson (1994). The measure they use can be viewed as a special case of the one we deploy in this paper; it presumes that all inter-group distances are "binary". In contrast, we will draw in detail on alternative measures of inter-group distances. Fearon (2003) has already made the point that ethnolinguistic distances may potentially play a role in explaining ethnic conflict and computed a measure based on dissimilarity between pairs of languages. Desmet et al. (2009) examine this point in a different context, by studying the level of social transfers in ethnically heterogeneous societies. They find that the measures that include variation in distances outperform the ones that don't.

${ }^{5}$ Recall Horowitz (1985): "A centrally focused system [with few groupings] possesses fewer cleavages than a dispersed system, but those it possesses run through the whole society and are of greater magnitude."
} 
briefly in Section 2. They show (see Proposition 1 below) that the equilibrium intensity of conflict is linearly related to just three measures of distribution and no other: polarization $(P)$, fractionalization $(F)$ and a Greenberg-Gini index of ethnic difference $(G)$, all to be formally defined below. Moreover, the model tells us that the weight of each of these indices in explaining conflict intensity depends on the particular nature of each conflict. Specifically, ethnic polarization will influence conflict if the prize is public and group cohesion is high, and ethnic fractionalization will influence conflict if the prize is private (and group cohesion, once again, is high). Finally, the Greenberg-Gini difference index becomes relatively important in explaining conflict if group cohesion is low.

The purpose of the current paper is to bring these theoretical predictions to the data. We study 138 countries over 1960-2008. We begin by implementing the idea that the equilibrium level of conflict is linked to the three distributional measures identified above. Across a variety of specifications and robustness checks (described in Tables 1-8), the ethnic polarization measure is highly significant and positive, the effect of fractionalization is equally large and positive though somewhat less significant, and the Greenberg-Gini, while significant, affects conflict negatively. The fact that polarization is strongly significant suggests that disputes over public goods, broadly defined, is an important feature of social conflicts. Such public goods could be narrowly economic, such as access to a particular trade or a labor market, or they could represent political power or cultural dominance, or plain animosity. The fact that fractionalization is significant as well suggests that divisible pecuniary benefits also play a role in conflict. Finally, the importance of polarization and fractionalization, and the fact that $G$ enters negatively can together be interpreted, using the theory, as an indicator that within-group cohesion in the contribution of conflict resources is particularly high in situations of open conflict.

Recall that the relative importance of $P$ and $F$ in explaining conflict depends on the extent to which payoffs are public rather than private. The previous exercise implicitly assumes that this composition is the same across countries. In the remainder of the paper, we take the analysis a step forward by constructing proxies for country-specific values of relative publicness from ancillary data. To do so, we employ indicators for privateness or publicness of the prize that vary across countries. We capture privateness by oil reserves, 
and publicness by different measures that attempt to capture the extent of autocracy (see Section 6 for more details). With these two sets of indicators we construct an index of relative publicness $\Lambda$. We use the structure of Proposition 1 to create the variables $P * \Lambda$ and $F *(1-\Lambda)$. These variables test for the ideas that the impact of polarization is heightened by relative publicness $\Lambda$, while that of fractionalization is enhanced by relative privateness $1-\Lambda$. Our second main result is that these assertions (see the first three columns of Table 9) are supported to a remarkable degree.

In the foregoing analysis, we continued to assume that the level of within-group cohesion is the same across the countries in our sample. In a last step that exploits fully the structure of the theory, we use indicators from the World Values Survey to estimate group cohesion by country, and then enter all these variables into the regression exactly as specified by the model. This permits sharper tests that rely even more deeply on the structure of the model. Once again, we invoke Proposition 1 to inform the empirical specification, and once again our results are strongly supportive of the theory; see the last three columns of Table 9. The three steps imply increasing faith in the logical structure of the model. We do not take a particular stand on this issue, and leave it to the reader to decide which approach (if any) she finds most convincing.

Section 2 summarizes the theory. Section 3 describes the data. Baseline empirical results are presented in Section 4, while Section 5 examines robustness along several dimensions. Section 6 extends the analysis to allow for inter-country variations in relative publicness and cohesion. Section 7 concludes.

\section{THEORY}

The background for this paper is Esteban and Ray (2011) [ER]. ER describe a theory of conflict incidence ${ }^{6}$ in which distributional measures play a central role. There are $m$ groups engaged in conflict, with $N_{i}$ the number of individuals in group $i$, and $N$ the total population. The winner enjoys two sorts of prizes: one is private and therefore excludable, and the other is public.

\footnotetext{
${ }^{6} \mathrm{It}$ is simply presumed that society is in a state of (greater or lesser) turmoil. For explicit models of the decision to enter into conflict, see Esteban and Ray (2007, 2008) and Ray (2009).
} 
Examples of private payoffs include administrative or political positions, specific tax breaks, bias in the allocation of public expenditure and infrastructures or access to rents from natural resources. Privateness has two properties. First, the prize is divided among the winning group, so group size matters (Olson, 1971). Second, the identity of the winner is irrelevant to the losers. ${ }^{7}$ Let $\mu$ be the per-capita value of the private prize at stake.

In most conflicts, victory also yields a prize that is public in nature, as its enjoyment is independent of the population size. This includes political power, control over policy, cultural values, religious dominance and so on. The (population-normalized) magnitude of such public payoffs - call it $\pi$ - must depend on the extent to which existing institutions permit the group in power to impose policies or values on the rest of society, repressing the culture of the groups in opposition. In general, other groups will derive utility from these choices, depending on "how far" they are from the winner. Say that a member of group $i$ enjoys payoff $u_{i j} \pi$ if the ideal policy of group $j$ is chosen. This induces a notion of "distance" across $i$ and $j: d_{i j} \equiv u_{i i}-u_{i j}$, so that the per-capita loss to $i$ of $j$ is just $\pi d_{i j}$.

Individuals in each group expend resources $r$ (time, effort, risk) to influence the final outcome. Write the income equivalent cost to such expenditure as $c(r)$ and assume that $c$ is increasing, smooth, and strictly convex, with $c^{\prime}(0)=0$. Add individual contributions in group $i$ to obtain group contribution $R_{i}$. We presume that the probability of success for group $i$ is given by $p_{i}=R_{i} / R_{N}$, where $R_{N} \equiv \sum_{i} R_{i}{ }^{8}$ We denote by $\rho \equiv R_{N} / N$ the per-capita value of the resources expended in conflict.

The payoff, then, to a person in group $i$ who expends resources $r$ is given by

$$
\pi u_{i i}+p_{i} \frac{\mu}{n_{i}}-\sum_{j=1}^{m} p_{j} \pi d_{i j}-c(r)
$$

where $n_{i} \equiv N_{i} / N$ is the population share of group $i$.

Close the model by presuming that every individual has an "extended utility function" (Sen, 1966) which places weight 1 on personal payoffs, described in (1), and weight $\alpha$ on the aggregate of all payoffs for other group members. As ER observe, the weight $\alpha$ could be

\footnotetext{
${ }^{7}$ To be sure, there could be differential degrees of resentment over the identity of the winner. Simply include this component under the public type of the two prizes.

${ }^{8}$ If $R_{N}=0$, use an arbitrary allocation of win probabilities.
} 
altruism, or some measure of the extent to which group monitoring, possibly with promises and threats, overcomes the usual free-rider problem. Indeed, $\alpha$ could exceed 1, the latter being the weight placed on the individual.

The main theoretical proposition to follow is based on three measures of ethnic divisions that are all based on the same underlying parameters: the population shares $n_{i}$ of each group, as well the intergroup distances $d_{i j}$ just defined. First, we introduce a measure of polarization based on Esteban and Ray (2004, 2011):

$$
P=\sum_{i=1}^{m} \sum_{j=1}^{m} n_{i}^{2} n_{j} d_{i j} .
$$

Next, we define the Greenberg-Gini index as

$$
G=\sum_{i=1}^{m} \sum_{j=1}^{m} n_{i} n_{j} d_{i j}
$$

The distinction between $P$ and $G$ is superficial at first sight but it is of great conceptual importance. The squaring of population shares in $P$ forces group sizes to matter over and above the mere counting of individual heads implicit in $G$.

Our last measure is ethnic fractionalization, which discards the inter-group distances from the Gini-Greenberg and replaces them with 0-1 variables:

$$
F=\sum_{i=1}^{m} \sum_{j \neq i} n_{i} n_{j}=\sum_{i=1}^{m} n_{i}\left(1-n_{i}\right)
$$

We can now state

Proposition 1 (Esteban and Ray, 2011). Equilibrium per-capita conflict $\rho$ is approximately determined as follows:

$$
\sigma \simeq \alpha[\lambda P+(1-\lambda) F]+\lambda(1-\alpha) \frac{G}{N}+\frac{(1-\lambda)(1-\alpha)(m-1)}{N},
$$

where $\sigma \equiv \frac{c^{\prime}(\rho) \rho}{\pi+\mu}$ is a measure of the intensity of conflict and $\lambda \equiv \pi /(\pi+\mu)$ is the relative publicness of the prize.

First interpret $\sigma$. The numerator is the income equivalent cost of the per capita level of resources employed in conflict, evaluated at the "shadow price" of these resources, $c^{\prime}(\rho)$ 
[the marginal rate of substitution of effort for income]. In the denominator we have the total per capita value of the stakes. We take the ratio of the value of the waste to the value of the potential benefits, $\sigma$, as an appropriate indicator for the intensity of conflict.

We now focus on the RHS of (2). The equilibrium level of conflict intensity depends on the exogenous data of the model: individual preferences, group size, the nature and the size of the prize, and level of group cohesion. This result tells us that all this information interacts in a very special way to determine equilibrium conflict intensity. It suffices to aggregate all the information on preferences and group sizes into just three indices $-P$, $F$, and $G / N$ - while the weights on the three distributional measures depend on the composition of the prize and on the level of group commitment. In particular, publicness of the prize reinforces the effect of polarization, privateness of the prize reinforces the effect of fractionalization, while high group cohesion enhances both measures and simultaneously diminishes the effect of $G / N$. ER discuss these effects in detail.

\section{Empirical Implementation: Data and Conceptual Issues}

We study 138 countries over 1960-2008. The time period is divided into five-year subperiods ${ }^{9}$ for a total of 1125 observations (in most cases). We start by considering several indicators for the intensity of conflict and then we deal with the measurement of group size and inter-group distances needed to compute the distributional indices. The discussion of the measurement of the degree of publicness of the price and of the level of group commitment is postponed to Section 6, when they will play a role in our estimations. The Appendix contains detailed descriptions of all the variables employed in the empirical analysis, as well as summary statistics pertaining to them.

3.1. Conflict. We measure intensity of conflict on the basis of the death toll. We use data on battle deaths from the UCDP/PRIO dataset. ${ }^{10}$ Ideally we would like to have

\footnotetext{
${ }_{9}$ The last subdivision, 2005-2008, contains only four years.

${ }^{10}$ This is a joint dataset of the Uppsala Conflict Data Program (UCDP) at the Department of Peace and Conflict Research, Uppsala University and the Centre for the Study of Civil War at the International Peace Research Institute, Oslo (PRIO). It is available at http://www.prio.no/Data/. See Gleditsch et al. (2002) for a presentation of the dataset and the relevant definitions. Correlates of War (COW) is an alternative dataset. It has been used by Doyle and Sambanis (2000), Collier and Hoefller (2002), and Fearon and Laitin (2003).
} 
information on the total number of deaths per year as a proper indicator for the intensity of conflict as captured in the ER model presented in Section 2. Unfortunately, available information is quite limited and unreliable. This has lead to the convention of measuring conflict by a binary variable. The PRIO dataset offers a yearly binary indicator of whether there is conflict or peace based on three threshold levels depending on the number of deaths: "low" (PRIO25), "intermediate" (PRIOCW), and "war" (PRIO1000). ${ }^{11}$ In the current exercise, a country is recorded as having experienced a conflict incidence at some level in a given period if in any of the years within that period the corresponding threshold condition has been met. ${ }^{12}$

We take as our baseline PRIO25, which reports all conflicts with 25 or more battle deaths in a year. Higher thresholds remove the small- and intermediate-intensity conflict events that the model also seeks to explain. At the same time we are sensitive to the need for alternative definitions, and report results on them. These include not just the higher-threshold definitions used by PRIO, but also non-binary alternatives both based on PRIO and from other data sources. See Section 5.1, in which these alternatives are first introduced.

These are measures of conflict incidence. Conflict onset is a separate notion: it describes the start of a "fresh episode" of war or violence. Our theory does not comfortably fit this particular concept as it is constructed to explain the intensity of conflict and not the decision of triggering it. Nevertheless, in the interest of robustness, we provide results in Section 5.4 for various definitions of onset provided by PRIO.

3.2. Distributional Indices. Our core independent variables are the indices $G, F$, and $P$, though in line with Proposition 1, the index $G$ enters the regression divided by total population, $N$, expressed in millions. In order to compute these indices we need the relevant groups for every country and a proxy for the "distance" in preferences across groups.

\footnotetext{
${ }^{11}$ PRIO considers a country to be in a state of conflict when one of the warring parties is the incumbent government and the number of battle-related casualties goes beyond a threshold as described in the main text.

${ }^{12}$ We note with some misgivings that the PRIO thresholds are not normalized by the population of the country in question, which undoubtedly biases civil wars in favor of large countries. The population control in our exercises should take care of this problem.
} 
3.2.1. Groups. Our analysis is based on data generously furnished by James Fearon. This dataset is an update of the one in Fearon (2003), which identifies over 800 "ethnic and ethnoreligious" groups in 160 countries. ${ }^{13}$ Fearon compares his groupings with other similar efforts; see Atlas Narodov Mira, Gurr (1996) and Alesina et al (2003). While recognizing that many "ethnic" classifications today are an inescapable product of history, he notes: "If there are multiple plausible ways of listing a country's 'ethnic groups', we must be careful that we do not, in effect, choose the coding that best supports our theory, after the fact." Throughout, there is a conscious effort to get at a classification that is deeply rooted in everyday recognition of existing groupings, yet not guided in any way by the existence of inter-group antagonisms. In our opinion, this is one of the most careful attempts to describe ethnic divisions, with no particular focus on ethnic conflict in the description.

We adopt the Fearon classification with no changes, though with some natural reservations. We test the robustness of our findings in Section 5.2 by using raw information on the size of different linguistic groups — and linguistic distances across those groups provided by Ethnologue.

3.2.2. Preferences and Distances. Next comes the construction of inter-group distances. Ideally, as discussed in Section 2, we would like to have distances induced by preferences over public goods. But there is no data on such preferences, and if there were, they would necessarily be plagued by endogeneity. A history of conflict presumably contributes to sizable inter-group "distances" in attitudes. In an attempt to avoid such problems, we follow Greenberg (1956), Fearon and Laitin (1999, 2000), Laitin (2000), Fearon (2003) and Desmet et al. (2009, 2010), and employ the linguistic distance between two groups as an appropriate indicator for their difference in preferences over public goods.

The different languages spoken can be organized in a language tree capturing their genealogy. All Indo-European languages, for instance, will belong to a common subtree.

\footnotetext{
${ }^{13}$ Attention is restricted to groups which account for over $1 \%$ of country population. The average number of ethnic groups per country is around 5 , with half the countries housing $3-5$ groups, though the African average exceeds 8 . About $70 \%$ of countries have a single ethnic group which is a majority, though in most cases the largest minority is pretty large: only around $20 \%$ of all countries have a single group that accounts for over $90 \%$ of the population.
} 
Subsequent splits create futher "sub-subtrees", down to the current language map. ${ }^{14}$ Ethnologue reports a maximum of fifteen steps of branching, though of course, not all modern language families hit this upper bound along their own evolutionary branch. ${ }^{15}$ The distance between two "cultures" can be approximated by lack of proximity on the language tree. Specifically, define the similarity between two languages $i$ and $j, s_{i j}$, as the ratio of the number of common branches to the maximum possible number - fifteen for the entire tree. $^{16}$ Then, following Fearon (2003) and Desmet et al. (2009), we define the distance between the two languages, $\kappa_{i j}$, as $\kappa_{i j}=1-s_{i j}^{\delta}$, for some parameter $\delta>0$. These translate directly into inter-group distances by assigning each group to its dominant language.

Fearon computes distances using $\delta=0.5$ and Desmet et al. $(2009,2010)$ use $\delta=0.05$. We shall take as a baseline the value $\delta=0.05$, for reasons that are discussed in greater detail In Section 5.3.

3.3. Additional Variables. The literature uses a variety of controls, to a large extent depending on the specific hypothesis being tested. We take as our baseline the set of controls used by MRQ, that is: log population (POP), log GDP per capita (GDPPC), a dummy for oil/diamond production (OIL/DIAM), percentage of mountainous terrain (MOUNT), noncontiguity of country territory (NCONTIG), and democracy (DEM). In all the specifications, the controls are measured in the first year of each period. As a robustness check, we also use fewer controls in some specifications and additional controls in others, such as governance variables from POLITY IV and Freedom House. ${ }^{17}$ The online Appendix also replicates our exercises with controls used in Fearon and Laitin (2003) and Collier et al (2009). We also construct estimates of group concern from the World Values Survey, as well as indices of relative publicness of the prize, based on data from Polity IV and Freedom House, and of

\footnotetext{
${ }^{14}$ For instance, Spanish and Basque diverge at the first branch, since they come from structurally unrelated language families. By contrast, the Spanish and Catalan branches share their first 7 nodes: Indo-European, Italic, Romance, Italo-Western, Western, Gallo-Iberian and Ibero-Romance languages.

${ }^{15}$ The interested reader can find a detailed discussion of the language tree in Desmet et al. (2009).

${ }^{16}$ If two groups speak the same language, $s_{i j}$ is set to 1 .

${ }^{17}$ More specifically, we consider the lack of executive constraints (EXCONS) and the level of autocracy (AUTOCR), both from POLITY IV, and the extent of suppression of civil liberties (CIVLIB) and political rights (POLRIGHTS) from Freedom House. Following Besley and Persson (2010), we use time-invariant versions of these variables, since short-run changes are likely to be correlated with the incidence of conflict. See Section 6 and the Appendix for more details on the construction of these variables.
} 
privateness of the prize, using data on oil reserves from Haber and Menaldo (2011). These variables will serve as essential ingredients for the analysis of Section 6 that exploits the structure of the model more deeply.

A more detailed definition of the control variables is included in the Appendix.

\section{BASELINE FindingS}

4.1. Specification. The goal of our exercise is to take equation (2) to the data as follows:

$$
\sigma_{i t}=X_{1 i t} \beta_{1}+X_{2 i t} \beta_{2}+\varepsilon_{i t}, i=1, \ldots, C, t=1, \ldots, T \text {, }
$$

where $X_{1 i t}$ are the relevant distributional variables in the model, $X_{2 i t}$ is a collection of controls, $\varepsilon_{i t}$ is an innovation, and $C$ and $T$ are number of countries and of time periods respectively. But we don't observe the dependent variable as written. Instead we will consider intensity of conflict as a latent variable that we infer from the realizations of the PRIO binary variables, presuming that

$$
P\left(\mathrm{PRIO}_{i t}=1 \mid X_{i t}\right)=P\left(\sigma_{i t}>W^{*} \mid X_{i t}\right)=H\left(X_{i t} \beta-W^{*}\right)
$$

where $X_{i t}=\left(X_{1 i t}, X_{2 i t}\right), W^{*}$ is a threshold that becomes an intercept in $\mathrm{H}, \beta$ is the vector of coefficients of interest and $H$ is the cdf of $\varepsilon_{i t}$ with symmetric pdf. ${ }^{18}$ To begin with, the variables $X_{1 i t}$ are the different distributional indices $P, F$ and $G / N$. This is our baseline specification, which effectively presumes that cohesion and the importance of public goods are the same across countries. Later, in Section 6, we relax this restriction.

4.2. Baseline. Our primary dependent variable uses various measures of conflict incidence. To be sure, incidence is deeply affected by past conflict, so we use lagged conflict as an additional control in all our (incidence) specifications. Table 1 reports our baseline results with Fearon groups and linguistic distances using $\delta=0.05$. In all cases, we compute $p$-values (in parentheses) using robust standard errors adjusted for clustering at the country level. Each column of the table contains our basic specification with the distributional indices $P, F$ and $G / N$. The columns differ in that we progressively add controls. See

\footnotetext{
${ }^{18}$ When using a nonbinary indicator, we shall have two thresholds associated with two intensity levels.
} 


\begin{tabular}{|c|c|c|c|c|c|c|c|}
\hline Variable & {$[1]$} & {$[2]$} & {$[3]$} & {$[4]$} & {$[5]$} & {$[6]$} & {$[7]$} \\
\hline$P$ & $\begin{array}{r}* * * 7.73 \\
(0.005)\end{array}$ & 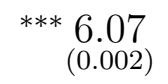 & $\begin{array}{r}* * * 6.90 \\
\quad(0.000)\end{array}$ & $\begin{array}{r}* * * 6.96 \\
\quad(0.001)\end{array}$ & $\begin{array}{r}* * * 7.38 \\
(0.001)\end{array}$ & $\begin{array}{r}* * * 7.39 \\
\quad(0.001)\end{array}$ & $\begin{array}{r}* * * \quad 6.50 \\
(0.004)\end{array}$ \\
\hline$F$ & $\begin{array}{r}* * * \\
(0.000)\end{array}$ & $\begin{array}{r}* * * \\
1.86 \\
(0.000)\end{array}$ & ${ }^{* *} 1.13$ & $\begin{array}{r}* * \\
(0.042)\end{array}$ & ${ }^{* *} \underset{(0.012)}{1.30}$ & $\begin{array}{r}* * \\
\quad 1.30 \\
(0.012)\end{array}$ & $\begin{array}{c}* * \\
\quad 1.25 \\
(0.020)\end{array}$ \\
\hline$G / N$ & $\begin{array}{r}*-6.95 \\
(0.067)\end{array}$ & $\begin{array}{r}* * \\
-5.47 \\
(0.011)\end{array}$ & $\begin{array}{c}*-4.37 \\
(0.077)\end{array}$ & $\begin{array}{r}*-4.45 \\
(0.071)\end{array}$ & $\begin{array}{r}*-4.77 \\
(0.072)\end{array}$ & $\begin{array}{r}*-4.80 \\
(0.068)\end{array}$ & $\begin{array}{r}*-5.09 \\
(0.074)\end{array}$ \\
\hline POP & $\begin{array}{r}* * * 0.30 \\
\quad(0.009)\end{array}$ & $\begin{array}{r}* * 0.19 \\
\quad(0.014)\end{array}$ & ** 0.23 & $\begin{array}{r}* * \\
\quad 0.22 \\
(0.012)\end{array}$ & $\begin{array}{c}0.13 \\
(0.141)\end{array}$ & $\begin{array}{c}0.13 \\
(0.141)\end{array}$ & $\begin{array}{c}0.14 \\
(0.131)\end{array}$ \\
\hline GDPPC & - & - & ***- $\begin{array}{r}0.40 \\
(0.001)\end{array}$ & $\begin{array}{r}* * * \\
(0.002)\end{array}$ & $\begin{array}{r}* * * \\
(0.001)\end{array}$ & $\begin{array}{r}* * *-0.47 \\
(0.001)\end{array}$ & $\begin{array}{c}* *-0.38 \\
(0.011)\end{array}$ \\
\hline OIL/DIAM & - & - & - & $\begin{array}{c}0.06 \\
(0.777)\end{array}$ & $\begin{array}{c}0.04 \\
(0.858)\end{array}$ & $\begin{array}{c}0.04 \\
(0.870)\end{array}$ & $\begin{array}{r}-0.10 \\
(0.643)\end{array}$ \\
\hline MOUNT & - & - & - & - & $\begin{array}{c}0.01 \\
(0.134)\end{array}$ & $\begin{array}{c}0.01 \\
(0.136)\end{array}$ & $\begin{array}{c}0.01 \\
(0.145)\end{array}$ \\
\hline NCONT & - & - & - & - & $\begin{array}{r}* * \\
\quad 0.84 \\
(0.019)\end{array}$ & $\begin{array}{c}* * 0.85 \\
(0.018)\end{array}$ & $* * * \begin{array}{r}0.90 \\
(0.011)\end{array}$ \\
\hline DEMOC & - & - & - & - & - & $\begin{array}{r}-0.02 \\
(0.944)\end{array}$ & $\begin{array}{c}0.02 \\
(0.944)\end{array}$ \\
\hline EXCONS & - & - & - & - & - & - & $\begin{array}{r}-0.13 \\
(0.741)\end{array}$ \\
\hline AUTOCR & - & - & - & - & - & - & $\begin{array}{c}0.14 \\
(0.609)\end{array}$ \\
\hline POLRIGHTS & - & - & - & - & - & - & $\begin{array}{c}0.17 \\
(0.614)\end{array}$ \\
\hline CIVLIB & - & - & - & - & - & - & $\begin{array}{c}0.16 \\
(0.666)\end{array}$ \\
\hline LAG & - & $\begin{array}{c}* * * \\
(0.000)\end{array}$ & $\begin{array}{r}* * * 2 \\
2.81 \\
(0.000)\end{array}$ & *** 2.80 & $\begin{array}{rl}* * * & 2.73 \\
(0.000)\end{array}$ & $\begin{array}{c}* * * \\
(0.000)\end{array}$ & $\begin{array}{r}* * * \\
(0.000)\end{array}$ \\
\hline CONST & ***- 7.28 & *** -6.20 & $\begin{array}{r}* * \\
-3.33 \\
(0.023)\end{array}$ & $\begin{array}{r}* *-3.20 \\
(0.028)\end{array}$ & $\begin{array}{c}-1.47 \\
(0.326)\end{array}$ & $\begin{array}{c}-1.49 \\
(0.322)\end{array}$ & $\begin{array}{r}-2.42 \\
(0.147)\end{array}$ \\
\hline Pseu-R ${ }^{2}$ & 0.13 & 0.37 & 0.38 & 0.38 & 0.39 & 0.39 & 0.40 \\
\hline Obs & 1289 & 1149 & 1125 & 1125 & 1125 & 1125 & 1013 \\
\hline$C$ & 141 & 141 & 138 & 138 & 138 & 138 & 137 \\
\hline
\end{tabular}

TABLE 1. Baseline specification with PRIO25, Fearon groupings.

Notes. $p$-values are reported in brackets. Robust standard errors adjusted for clustering have been employed to compute $z$-statistics.

Appendix for descriptions of these variables. Column 1 uses no controls except for population, and Column 2 adds in lagged conflict. Column 3 adds per-capita GDP. Column 4 factors in resources: a dummy variable for whether the country is a producer of oil or diamonds. ${ }^{19}$ Column 5 brings in geographical controls: mountainous terrain and whether a country has regions separated by land or water ("noncontiguity"). Column 6 adds the

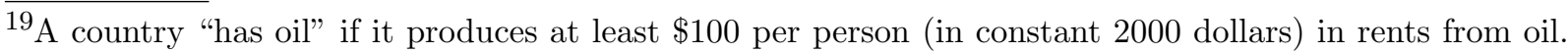
A country "has diamonds" if diamonds are produced locally. We take this information from Ross (2006). 
standard political control for democracy. At this stage, the set of controls we use is in line with MRQ, and we use this as our baseline control set. Column 7 adds in more political and governance controls.

Throughout, $P, F$ and $G / N$ are significant. $P$ has the expected positive coefficient and is highly significant. The coefficient associated with $F$ is also positive. $G / N$, while also significant, has negative sign; we interpret this below. Moreover, lagged conflict is highly significant and, in line with a common result in all the literature on conflict with crosscountry data, per-capita income is significantly and negatively correlated with conflict. ${ }^{20}$ Finally, we do not see a direct effect of natural resources, though when this is used to constructed a measure of relative publicness and interacted with distributional measures in the way suggested by the theory, it will have a highly significant impact (see Table 9).

Using the theory summarized in Proposition 1 and the assumption that $\alpha$ and $\lambda$ are constant across countries, it is possible to provide an interpretation for the estimated parameters. First, the fact that $P$ is highly significant suggests that both the publicness of the prize $(\lambda)$ as well as the degree of group cohesion $(\alpha)$ are significant. Moreover, our results for $G / N$ suggest that $\alpha$ is close to 1 or perhaps even larger than it, indicating that models of free-riding are perhaps less relevant than we make them out to be, at least in the cases of civil conflict in the data. ${ }^{21}$ One obvious possibility is selection: observed conflicts must have been successful in resolving the collective action problem, so that such conflicts must be associated with a high value of group cohesion.

As for the public component, whether it is economic (control of a labor or housing market, or a trade), cultural (the establishment of some notion of ideological or religious superiority) or political (control of the state) is something we cannot identify. All we can say is that it is central to conflict. At the same time, the significance of $F$ suggests that private components, such as the existence of natural resources, are also important. While natural resources in and of themselves are not significant in our regressions, we shall see

\footnotetext{
${ }^{20}$ We have also examined the effect of income inequality. Using the Gini of personal incomes as a regressor has no effect neither on the value of the coefficient corresponding to $P$ nor on its significance, always at $1 \%$.

${ }^{21}$ The observation that $\alpha>1$ means that individuals might effectively be placing more weight on the group than they do on themselves.
} 
in Section 6 that they come fully into their own when interacted with the distributional variables as directed by the theory.

Our interpretation — that both public and private goods matter for conflict — is relevant to the discussion on greed versus grievance as motivations for ethnic conflict introduced by Collier and Hoeffler. ${ }^{22}$ While we are not sure of the utility of this distinction, one possible interpretation is that "greed" corresponds to conflict over private goods, while "grievance" would come under the rubric of public goods (political rights and freedoms, or religious dominance). Our exercise points to the importance of both motives and this will be further enhanced as we exploit the model structure even further in Section 6.

Finally, we point to the quantitative importance of polarization and fractionalization in conflict. Consider the baseline set of controls (Column 6). Our estimated coefficients imply that if we move from the 20th percentile of polarization to the 80th percentile, holding all other variables at their means, the probability of conflict rises from approximately $13 \%$ to $29 \%$. Performing the same exercise for $F$ takes us from $12 \%$ to $25 \%$. These are remarkably similar (and strong) effects.

4.3. Country Examples and Scatters. Here are some country-specific examples to accompany the main findings of Table 1. This is an interesting task, as both polarization and fractionalization are positively related to conflict, but they are related to each other in a nonmonotonic way. Our strategy, then, is to work off the marginals (polarization controlling for fractionalization, and vice versa).

Chile exhibits the median fractionalization in our country set. If we focus on countries in the 45-55 percentiles of $F$ and rank these countries in increasing order of polarization, we obtain the list in Table 2(a). Similarly, Taiwan exhibits the median polarization in the sample. Once again, if we restrict attention to countries in the $45-55$ percentiles of $P$ and rank them in increasing order of fractionalization, we obtain the list in Table 2(b). In each case, the first numerical column lists the intensity of conflict (at the worst point during 1960-2008): 0 when deaths fall below the PRIO25 threshold, 1 when that threshold is crossed but not the higher PRIO1000 mark, and 2 when the latter threshold is exceeded.

\footnotetext{
$\overline{{ }^{22} \text { See Collier }}$ and Hoeffler (2004) and — more recently — Collier et al. (2009).
} 


\begin{tabular}{lrr}
\hline Part A & Intensity & Years \\
\hline Dom Rep & 1 & 1 \\
Morocco & 1 & 15 \\
USA & 0 & 0 \\
Serbia-Mont & 2 & 2 \\
Spain & 1 & 5 \\
Macedonia & 1 & 1 \\
Chile & 1 & 1 \\
Panama & 1 & 1 \\
Nepal & 2 & 14 \\
Canada & 0 & 0 \\
Myanmar & 2 & 117 \\
Kyrgystan & 0 & 0 \\
Sri Lanka & 2 & 26 \\
Estonia & 0 & 0 \\
Guatemala & 1 & 30 \\
\hline
\end{tabular}

\begin{tabular}{lrr}
\hline Part B & Intensity & Years \\
\hline Germany & 0 & 0 \\
Armenia & 0 & 0 \\
Austria & 0 & 0 \\
Taiwan & 0 & 0 \\
Algeria & 2 & 22 \\
Zimbabwe & 2 & 9 \\
Belgium & 0 & 0 \\
USA & 0 & 0 \\
Morocco & 1 & 15 \\
Serbia-Mont & 2 & 2 \\
Latvia & 0 & 0 \\
Trin-Tob & 1 & 1 \\
Guinea-Bissau & 1 & 13 \\
Sierra Leone & 2 & 10 \\
Mozambique & 2 & 27 \\
\hline
\end{tabular}

TABle 2. Distribution and Conflict With Country Examples.

Notes. Part A ranks the median fractionalization decile in increasing order of polarization.

Part B ranks the median polarization decile in increasing order of fractionalization.

The second numerical column records the number of years of conflict incidence in the period 1960-2008: it could well exceed the total number of years in the sample (as in the case of Myanmar) if there are multiple conflicts.

Even with no other controls in this table, it is fair to say that the results are supportive of the econometric findings in Table 1 and in the tables to follow. Controlling for fractionalization, higher polarization goes with higher conflict, and the same is true of fractionalization once we control for polarization.

To be sure, it is too much to assert that every conflict in our dataset is ethnic in nature, and that our ethnic variables capture them fully. ${ }^{23}$ Consider China, or Haiti, or undivided Korea, which have experienced conflict and yet have low polarization and fractionalization. All conflict is not ethnic. What is remarkable is that many of them are.

\footnotetext{
${ }^{23}$ To explore whether our results are driven by a particular group of observations, we have employed several tools to detect the influential observations in the sample. There are 78, 43 and 117 influential observations according to the Pearson residual, deviance residual and Pregibon leverage statistics, respectively. The online Appendix reproduces column [6] in Table 1 once influential observations have been removed from the sample. The significance of $P$ and $F$ remains unaffected.
} 


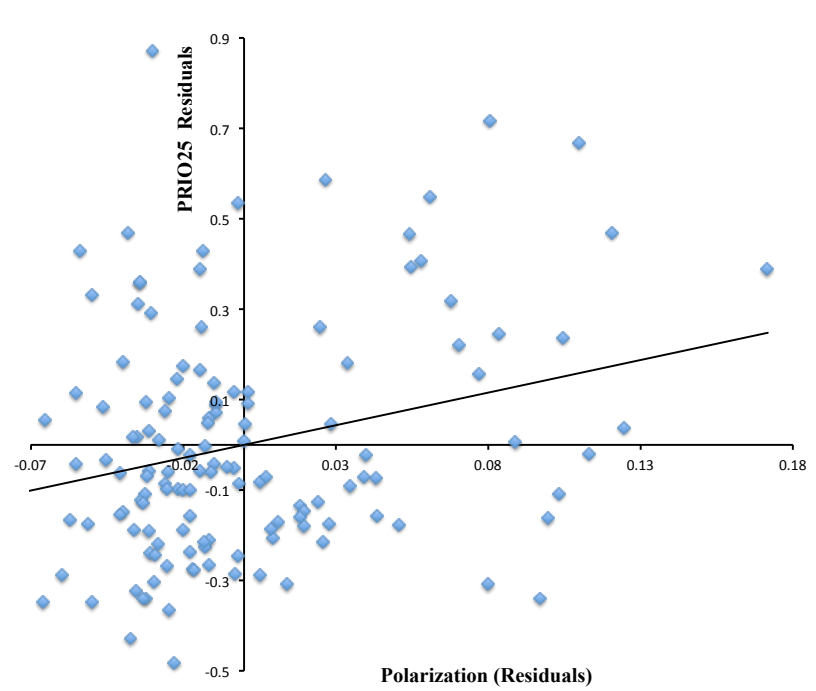

(A) Polarization and Conflict

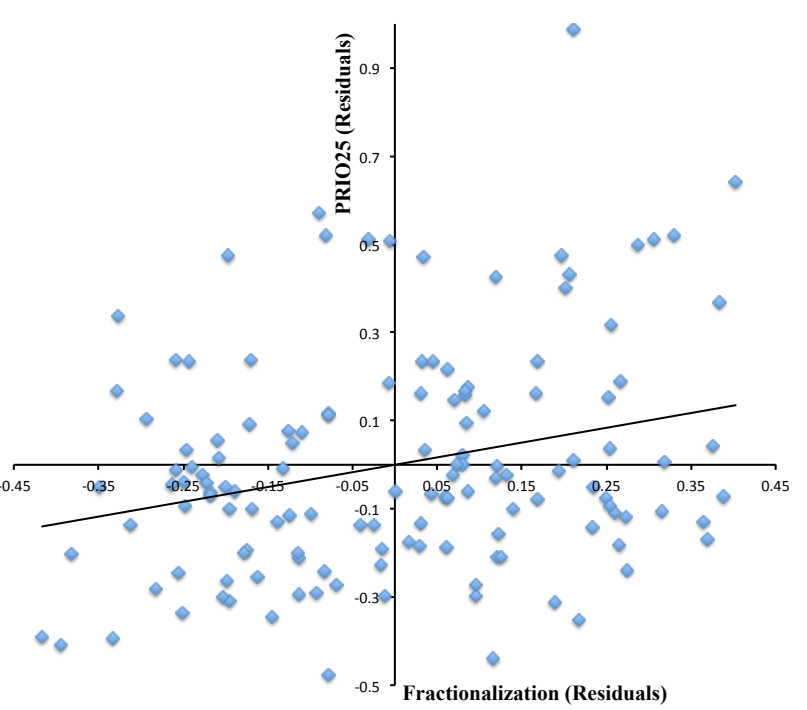

(в) Fractionalization and Conflict

Figure 1. Polarization, Fractionalization and Conflict.

We end this section by illustrating our baseline regression with scatter plots that capture the marginal effects of polarization and fractionalization on conflict. Figure 1 does this. Panel A shows how polarization is related to conflict, conditioning by other covariates. Panel B relates fractionalization to conflict in exactly the same way. The two scatters illustrate our baseline findings well. ${ }^{24}$

\section{Extensions and VARiations}

We analyze some variations to examine the robustness of the baseline in Table 1 . We study (a) alternative measures of conflict, (b) an alternative criterion for groups, (c) the choice of inter-group distances, (d) onset versus incidence, (e) controls for region and time, and (f) alternative estimation strategies.

5.1. Alternative Measures of Conflict. Our baseline uses the conflict binary variable PRIO25. PRIO reports other indicators, and non-binary alternatives are also possible. Table 3 reports on the use of alternative dependent variables to proxy conflict. Column 1

\footnotetext{
${ }^{24}$ Conflict is the average of PRIO25 over the sample. Time-varying covariates are referred to 1960 . The graphs plot the residuals from the linear regressions: Panel A, (1) P on all other covariates, (2) conflict on all other covariates (excluding P). Panel B (1) F on all other covariates, (2) conflict on all other covariates (excluding F).
} 


\begin{tabular}{|c|c|c|c|c|c|}
\hline Variable & {$[1]$} & {$[2]$} & [3] & {$[4]$} & {$[5]$} \\
\hline$P$ & $\begin{array}{r}* * * \\
\quad 7.39 \\
(0.001)\end{array}$ & 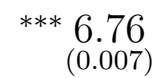 & $\begin{array}{r}* * * 10.47 \\
(0.001)\end{array}$ & $\begin{array}{r}* * * \quad 6.50 \\
(0.000)\end{array}$ & $\begin{array}{r}* * * 25.90 \\
(0.003)\end{array}$ \\
\hline$F$ & ${ }^{* *} \frac{1.30}{(0.012)}$ & ${ }^{* *} \frac{1.39}{(0.034)}$ & ${ }^{*} 1.11$ & *** 1.30 & $\begin{array}{l}2.27 \\
(0.187)\end{array}$ \\
\hline$G / N$ & $\begin{array}{r}*-4.80 \\
(0.068)\end{array}$ & $\begin{array}{c}-5.70 \\
(0.271)\end{array}$ & $\begin{array}{r}*-12.47 \\
(0.062)\end{array}$ & $\begin{array}{c}*-4.82 \\
(0.071)\end{array}$ & $\begin{array}{c}-2.09 \\
(0.399)\end{array}$ \\
\hline GDPPC & $\begin{array}{r}* * * \\
(0.001)\end{array}$ & $\begin{array}{r}*-0.35 \\
(0.066)\end{array}$ & $\begin{array}{r}* * * \\
(0.000)\end{array}$ & $\begin{array}{r}* * *-0.40 \\
(0.002)\end{array}$ & *** $-\underset{(0.001)}{1.70}$ \\
\hline POP & $\begin{array}{c}0.13 \\
(0.141)\end{array}$ & $\begin{array}{c}* 0.19 \\
(0.056)\end{array}$ & $\begin{array}{c}0.13 \\
(0.215)\end{array}$ & $\begin{array}{l}0.10 \\
(0.166)\end{array}$ & ${ }^{* * *} \begin{array}{c}1.11 \\
(0.000)\end{array}$ \\
\hline OIL/DIAM & $\begin{array}{c}0.04 \\
(0.870)\end{array}$ & $\begin{array}{c}0.06 \\
(0.825)\end{array}$ & $\begin{array}{r}-0.03 \\
(0.927)\end{array}$ & $\begin{array}{c}-0.04 \\
(0.816)\end{array}$ & $\begin{array}{r}-0.57 \\
(0.463)\end{array}$ \\
\hline MOUNT & $\begin{array}{c}0.01 \\
(0.136)\end{array}$ & $\begin{array}{r}* * \\
\quad 0.01 \\
(0.034)\end{array}$ & $\begin{array}{c}0.01 \\
(0.323)\end{array}$ & $\begin{array}{c}0.00 \\
(0.282)\end{array}$ & $* * \begin{array}{r}* 0.04 \\
(0.022)\end{array}$ \\
\hline NCONT & $\begin{array}{rl}* * & 0.85 \\
& (0.018)\end{array}$ & $\begin{array}{c}0.62 \\
(0.128)\end{array}$ & $\begin{array}{c}* 0.78 \\
(0.052)\end{array}$ & $\begin{array}{r}* 0.55 \\
(0.069)\end{array}$ & $\begin{array}{r}* * * 4.38 \\
(0.004)\end{array}$ \\
\hline DEMOC & $\begin{array}{r}-0.02 \\
(0.944)\end{array}$ & $\begin{array}{c}-0.09 \\
(0.790)\end{array}$ & $\begin{array}{c}-0.41 \\
(0.230)\end{array}$ & $\begin{array}{r}-0.03 \\
(0.909)\end{array}$ & $\begin{array}{c}0.06 \\
(0.944)\end{array}$ \\
\hline LAG & $\begin{array}{r}* * * 2.73 \\
(0.000)\end{array}$ & $\begin{array}{r}* * * 3.74 \\
(0.000)\end{array}$ & $\begin{array}{rl}* * * & 2.78 \\
(0.000)\end{array}$ & $\begin{array}{r}* * * 2.00 \\
(0.000)\end{array}$ & *** 0.50 \\
\hline CONST & $\begin{array}{c}-1.49 \\
(0.322)\end{array}$ & ${ }^{* *}-\begin{array}{c}4.28 \\
(0.017)\end{array}$ & -1.10 & - & $\begin{array}{r}-2.75 \\
(0.521)\end{array}$ \\
\hline$\left(\mathrm{Pseu}^{-}\right) \mathrm{R}^{2}$ & 0.39 & 0.50 & 0.38 & 0.34 & 0.41 \\
\hline Obs & 1125 & 1125 & 1125 & 1125 & 1111 \\
\hline C & 138 & 138 & 138 & 138 & 138 \\
\hline DepVar & PRIO25 & PRIOCW & PRIO1000 & PRIOINT & ISC \\
\hline
\end{tabular}

TABle 3. Different conflict variables, Fearon groupings.

Notes. Cols. 1-3, logit; Col. 4, ordered logit; Col. 5, OLS. p-values are reported in brackets. Robust standard errors adjusted for clustering have been employed to compute $z$-statistics.

repeats Column 6 from the baseline specification for comparison (the same controls are used here). Column 2 employs the intermediate notion PRIOCW, which is PRIO25 augmented by the requirement that the overall conflict must yield at least 1000 deaths. Column 3 uses PRIO1000, the PRIO definition of civil war, which demands at least 1000 deaths per year. Column 4 reports on a non-binary measure of intensity — PRIOINT — based on the PRIO dataset that separates conflict episodes satisfying PRIO1000 from the rest. "Peace" is assigned a value of 0, events satisfying PRIO25 that are not PRIO1000 are assigned 1, and events recorded as PRIO1000 are assigned 2. ${ }^{25}$ Finally, column 5 uses an alternative

${ }^{25}$ We do not use PRIOCW in the definition because it relies on the overall number of deaths, and does not necessarily imply a higher intensity in any particular year. 
measure of conflict intensity: the continuous index of social conflict, ISC, as computed by the Cross-National Time-Series Data Archive (CNTS). ${ }^{26}$ It provides a measure of the level of social unrest with no threshold dividing "peace" from "war". The index ISC is formed by taking a weighted average over eight different manifestations of internal conflict, adopted from Rummel (1963). For details of variables and weights, see the Appendix. ${ }^{27}$ As always in cases of incidence, we use lagged values of the conflict variable as a control, in addition to the other controls in Column 6 of Table 1.

Throughout, $P$ has the expected positive coefficient and is highly significant. $F$ is also positive and significant in most of the specifications. $G / N$ continues to have negative sign, but is not significant in most cases. Of course, lagged conflict continues to be highly significant, as is per-capita income. To obtain some idea of strengths: a move from the 20th percentile to the 80th percentile in polarization (keeping all other variables at their means) raises the probability of PRIOCW from approximately $7 \%$ to $17 \%$, while it increases the likelihood of PRIO1000 from under 3\% to a bit under 10\%. A corresponding change in fractionalization has similar effects: PRIOCW goes from under $7 \%$ to $16 \%$, while PRIO1000 increases from approximately $3 \%$ to $6 \%$.

While our results are generally robust to the choice of other dependent variables, we record our own preferences. The variable PRIO25 is generally useful, because it serves as a repository of all conflicts. In contrast, PRIO1000 will fail to register conflicts that run into hundreds of deaths per year. To be sure, the choice will depend on the questions being asked, but there is no way in which our theory allows us to eliminate (as examples) the Palestinian or Guatemalan conflicts, neither of which receive a coding in any year of the PRIO dataset (up to 2008) as a PRIO1000 conflict. Moreover, the cumulative deaths in all these cases is sizable. ${ }^{28}$ This motivates our strong preference for PRIO's own baseline definition of conflict using PRIO25, and in what follows, we will not emphasize PRIO1000 any longer.

\footnotetext{
${ }^{26}$ See Banks (2008).

${ }^{27}$ The correlation between ISC and PRIO25 is 0.52 and with PRIOINT is 0.57 .

${ }^{28}$ There are many other examples. To choose a current one, the Indian government has described the ongoing Maoist conflict in tribal areas as the greatest internal security threat to the country. Yet, while the conflict has been severe, with many killings, the annual numbers have been in the hundreds, but below the PRIO1000 threshold, as of 2010.
} 
Another option, and one that we have a distinct preference for, is the use of PRIOINT, which places larger weight on PRIO1000 conflicts as described above. We use PRIO25 only because it is standard, but PRIOINT performs just as well in every one of the regressions displayed for PRIO25. The online Appendix contains a full set of estimations using this variable.

5.2. Alternative Groupings. We have already discussed Fearon's (2003) classification of ethnic groups. It is one that we use with some confidence, because of the deep recognition of endogeneity in his discussion and the careful attempts made to avoid such issues. Yet, at some level, the ethnic groupings do reflect contemporary relevance. The cases of Rwanda, Burundi, or Somalia, in which there is full homogeneity in language, or of Papua, where no linguistic group reaches $1 \%$ of the population, clearly suggest that the definition of the "relevant" ethnic groups demands careful but active intervention by the researcher.

In the interests of robustness, we use entirely ungrouped raw information on the size of different linguistic groups — and linguistic groups alone - provided by Ethnologue. ${ }^{29}$ The Ethnologue project lists 6,912 known living languages and gives the population sizes that use each language in each country. ${ }^{30}$ Speaking a different language certainly sets a barrier with one's neighbor and can be considered a sound though distant base for differences in preferences for public goods. While it is ludicrous to suggest that modernday conflicts take place across the groups recorded in Ethnologue, it is reasonable to expect that such language distinctions could form the basis of cultural and social differences. The econometric advantage of that connection is obvious: it permits a more adequate defence of exogeneity, possibly at the expense of direct causality. This is a standard tradeoff. ${ }^{31}$

\footnotetext{
${ }^{29}$ The information from Ethnologue has already been used for the analysis of conflict by Alesina et al. (2003) and Desmet et al. (2009, 2010).

${ }^{30}$ For instance, in the case of Mexico, Ethnologue reports 291 living languages. In contrast, the number of ethnic groups for this country in Fearon's dataset is four (Mestizo, Amerindian, White and Mayans).

${ }^{31}$ An alternative approach, which we have examined with equal success for $P$, is to instrument for the distributional measures obtained from Fearon groupings using their counterparts from the Ethnologue classification. The first-stage correlations are high: for instance, the correlation between the two polarization indices (when $\delta=0.05$ in both cases) is equal to 0.70 . But we find it difficult to push the exclusion restriction that all linguistic sources of conflict must of necessity transmit themselves via the Fearon grouping, which, too, is a step removed from the groups directly engaged in conflict. We therefore restrict ourselves to simply reporting the reduced-form estimates using Ethnologue, as a robustness exercise.
} 


\begin{tabular}{|c|c|c|c|c|c|}
\hline Variable & [1] & {$[2]$} & {$[3]$} & [4] & [5] \\
\hline$P$ & $\begin{array}{rl}* * * & 8.26 \\
(0.001)\end{array}$ & $\begin{array}{r}* * * \\
8.17 \\
(0.005)\end{array}$ & ${ }^{* *} \underset{(0.016)}{10.10}$ & $\begin{array}{r}* * * 7.28 \\
(0.001)\end{array}$ & $\begin{array}{r}* * * 27.04 \\
(0.008)\end{array}$ \\
\hline$F$ & $\begin{array}{c}0.64 \\
(0.130)\end{array}$ & $\begin{array}{c}0.75 \\
(0.167)\end{array}$ & $\begin{array}{c}0.51 \\
(0.341)\end{array}$ & $\begin{array}{c}0.52 \\
(0.185)\end{array}$ & $\begin{array}{r}-0.58 \\
(0.685)\end{array}$ \\
\hline$G / N$ & $\begin{array}{c}-2.13 \\
(0.121)\end{array}$ & $\begin{array}{r}-1.59 \\
(0.389)\end{array}$ & $\begin{array}{c}-8.35 \\
(0.205)\end{array}$ & $\begin{array}{r}* 2.15 \\
(0.099)\end{array}$ & $\begin{array}{r}-0.26 \\
(0.907)\end{array}$ \\
\hline GDPPC & $\begin{array}{r}* * *-0.51 \\
(0.000)\end{array}$ & $\begin{array}{r}* * \\
-0.39 \\
(0.022)\end{array}$ & $\begin{array}{r}* * *-0.63 \\
(0.000)\end{array}$ & $\begin{array}{r}* * *-0.45 \\
(0.000)\end{array}$ & ***- 2.03 \\
\hline POP & $\begin{array}{r}* 0.15 \\
(0.100)\end{array}$ & $\begin{array}{r}* * 0.24 \\
(0.020)\end{array}$ & $\begin{array}{c}0.15 \\
(0.198)\end{array}$ & $\begin{array}{c}0.12 \\
(0.118)\end{array}$ & ${ }^{* * *} \underset{(0.000)}{1.20}$ \\
\hline OIL/DIAM & $\begin{array}{c}0.15 \\
(0.472)\end{array}$ & $\begin{array}{c}0.21 \\
(0.484)\end{array}$ & $\begin{array}{c}0.10 \\
(0.758)\end{array}$ & $\begin{array}{c}0.08 \\
(0.660)\end{array}$ & $\begin{array}{r}-0.06 \\
(0.943)\end{array}$ \\
\hline MOUNT & $\begin{array}{r}* 0.01 \\
(0.058)\end{array}$ & $\begin{array}{r}* * \\
0.01 \\
(0.015)\end{array}$ & $\begin{array}{c}0.01 \\
(0.247)\end{array}$ & $\begin{array}{l}* 0.01 \\
(0.099)\end{array}$ & $\begin{array}{r}* * 0.04 \\
(0.013)\end{array}$ \\
\hline NCONT & $\begin{array}{r}* * 0.72 \\
\quad(0.034)\end{array}$ & $\begin{array}{c}0.49 \\
(0.210)\end{array}$ & $\begin{array}{c}0.50 \\
(0.194)\end{array}$ & $\begin{array}{c}0.44 \\
(0.136)\end{array}$ & *** $\begin{array}{r}4.12 \\
(0.006)\end{array}$ \\
\hline DEMOC & $\begin{array}{c}0.03 \\
(0.906)\end{array}$ & $\begin{array}{c}0.00 \\
(0.993)\end{array}$ & $\begin{array}{r}-0.32 \\
(0.350)\end{array}$ & $\begin{array}{c}0.03 \\
(0.898)\end{array}$ & $\begin{array}{c}0.02 \\
(0.979)\end{array}$ \\
\hline LAG & $\begin{array}{r}* * * * \\
2.73 \\
(0.000)\end{array}$ & $\begin{array}{r}* * * \\
3.75 \\
(0.000)\end{array}$ & *** 2.83 & *** 2.01 & $* * * \begin{array}{r}0.50 \\
(0.000)\end{array}$ \\
\hline CONST & $-\frac{1.42}{(0.379)}$ & $* *-\begin{array}{c}4.62 \\
(0.018)\end{array}$ & -1.26 & - & $\begin{array}{r}-0.69 \\
(0.881)\end{array}$ \\
\hline$\left(\right.$ Pseu-) $R^{2}$ & 0.37 & 0.49 & 0.37 & 0.32 & 0.40 \\
\hline Obs & 1117 & 1117 & 1117 & 1117 & 1103 \\
\hline$C$ & 137 & 137 & 137 & 137 & 137 \\
\hline DepVar & PRIO25 & PRIOCW & PRIO1000 & PRIOINT & ISC \\
\hline
\end{tabular}

TABLE 4. Different conflict variables, Ethnologue groupings.

Notes. Cols. 1-3, logit; Col. 4, ordered logit; Col. 5, OLS. p-values are reported in brackets. Robust standard errors adjusted for clustering have been employed to compute $z$-statistics.

Table 4 exactly replicates Table 3 using the group sizes furnished by Ethnologue. The behavior of the polarization index $P$, as well as that of $G / N$, is unchanged. In particular, polarization continues to be as significant as in our previous exercise. (Even the estimated coefficients are very close.) But fractionalization is no longer significant. This is not surprising. Indices that fail to take inter-group distances into account are less robust to the definition of groupings. We return to this issue in the next subsection.

5.3. Group Distances. A separate concern is the robustness of our results with respect to the parameter $\delta$ for the distance variable. We use $\delta=0.05$, as do Desmet et al. (2009). Fearon (2003) uses $\delta=0.5$. None of these choices is satisfactorily motivated. Yet the 


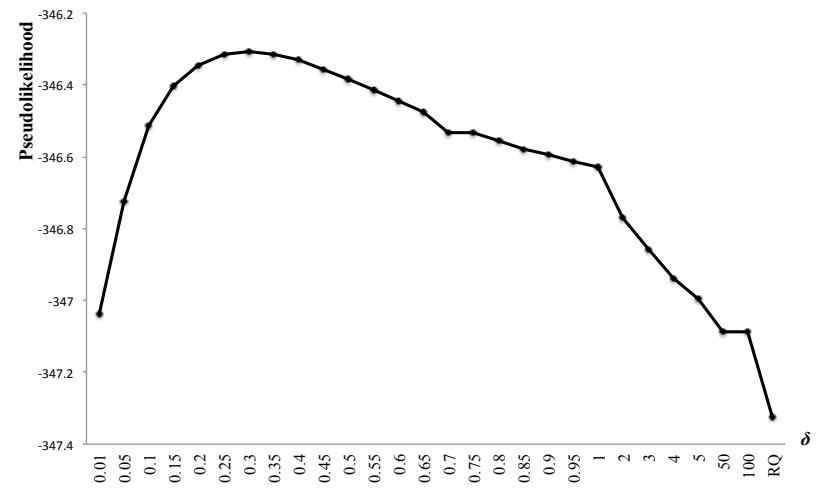

(A) Fearon groupings

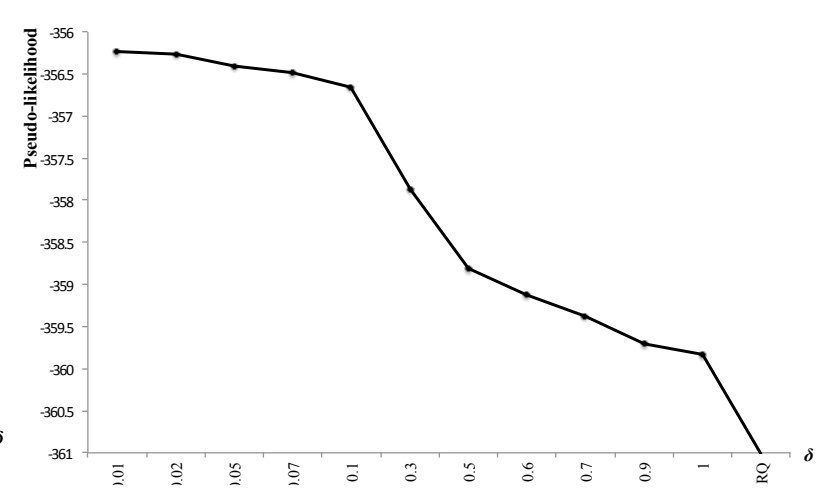

(B) Ethnologue groupings

Figure 2. Pseudolikelihoods for Different values of $\delta$.

choice is important because it implicitly selects the levels of linguistic (dis)similarity to be emphasized. Low values of $\delta$ will essentially separate the languages that have very few branches in common from the rest. As we progressively increase $\delta$, small differences acquire greater salience while the bigger differences play a less than proportional role. In the limit as $\delta \rightarrow \infty$, the smallest difference is identified as a complete difference, indistinguishable from deeper linguistic cleavages. The polarization measure that corresponds to this limit would only use binary 0-1 "distances", and is at the heart of MRQ's empirical study:

$$
R=\sum_{i=1}^{m} \sum_{j \neq i}^{m} n_{i} n_{j}=\sum_{i=1}^{m} n_{i}^{2}\left(1-n_{i}\right)
$$

In a sense, it is possible to treat $\delta$ as a parameter and estimate it. ${ }^{32}$ Following Hansen (1996), consider a grid of values of $\delta \in(0, \infty)$, which generate associated values for $P$ and $G$, and estimate the baseline specification for each of these values. The estimate of $\delta$ is the one for which the maximum value of the pseudo-likelihood is reached. We do not follow this estimation procedure, but it is worth inspecting the pseudo-likelihoods for different vales of $\delta .^{33}$

\footnotetext{
${ }^{32}$ Alternatively, one could re-estimate the model with other values of $\delta$ to check robustness. See the online Appendix for some exercises alone these lines.

${ }^{33}$ Formally, $\delta$ is only identified when the coefficients of $P$ or $G / N$ are different from zero. Selecting $\delta$ in a data-dependent fashion would require to use nonstandard asymptotic distributions and testing procedures to test for the significance of the regression coefficients, since the distributions of the conventional $t$ or $F$ tests would depend on unknown nuisance parameters, see Hansen (1996).
} 
Figure 2 reports these values for both the Fearon and Ethnologue groupings. Fearon comes pre-grouped, as it were: the small distances have already been removed in the choice of groupings themselves, so that the likelihood initially rises and is then relatively flat about its maximum value over a rather wide range, beginning with small values of $\delta$; see panel A. Our choice of $\delta=0.05$ is a perfectly reasonable choice under this criterion, but had we chosen another value in the range of the flat segment we would have done just as well in terms of fit. The Ethnologue grouping is different, however. Because every language forms a separate group, our fit is quite sensitive to the choice of $\delta$, and decays rapidly as we insist on emphasizing every language difference as important; i.e., as we raise the value of $\delta$; see panel $\mathrm{B}$ and note that the axes in panels (a) and (b) have very different scales.

We illustrate this argument in the special case of the "binary" polarization measure $R$ which, as we've noted, effectively sets $\delta=\infty$. The correlation between $P$ (with $\delta=0.05$ ) and $R$ is 0.45; see online Appendix for the scatter plot. In Table 5, Column 1 reproduces the baseline estimates for PRIO25 from Column 6 of Table 1, using the Fearon groupings. Column 2 replaces $P$ with the binary index $R$. The parallels between the two are evident: $R$ simply takes over from $P$. This column can be viewed as a replication of the basic equation in MRQ. Column 3 of the table puts together both $P$ and $R$ along with the other distributional equations into a single equation. The comparison continues to yield symmetric outcomes: now $P$ and $R$ are both significant, and on very similar terms. Thus, while $P$ is a powerful explanatory variable, so — it seems - is $R$.

There is a striking difference, however, once we employ classifications based on completely ungrouped linguistic criteria. Now it is imperative to carry a notion of distance, otherwise every pair of groups will appear equally distinct. To see this, consider our specification using Ethnologue; we've reproduced Column 1 from Table 4 as Column 4 here. Once again $P$ is highly significant. But this time the replacement of $P$ by $R$ in Column 5 is not met with equal success, or indeed with any success at all. $R$ is entirely insignificant. Finally, the horse-race between $P$ and $R$ in Column 6 is unambiguously resolved in favor of $P: R$ plays no role at all. 


\begin{tabular}{|c|c|c|c|c|c|c|}
\hline Variable & [1] & {$[2]$} & {$[3]$} & {$[4]$} & {$[5]$} & {$[6]$} \\
\hline$P$ & 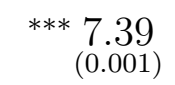 & - & 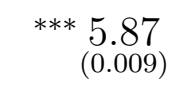 & 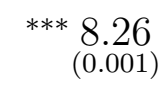 & - & *** 9.02 \\
\hline$F$ & ** $\begin{array}{c}1.30 \\
(0.012)\end{array}$ & $\begin{array}{c}0.45 \\
(0.493)\end{array}$ & $\begin{array}{c}0.56 \\
(0.388)\end{array}$ & $\begin{array}{c}0.64 \\
(0.130)\end{array}$ & $\begin{array}{c}0.63 \\
(0.192)\end{array}$ & $\begin{array}{c}0.79 \\
(0.108)\end{array}$ \\
\hline$R$ & - & $\begin{array}{r}* * * \begin{array}{r}7.13 \\
(0.004)\end{array}\end{array}$ & $\begin{array}{c}* * \\
5.12 \\
(0.046)\end{array}$ & - & $\begin{array}{c}1.09 \\
(0.560)\end{array}$ & $\begin{array}{r}-1.52 \\
(0.418)\end{array}$ \\
\hline$G / N$ & $\begin{array}{r}*-4.80 \\
(0.068)\end{array}$ & $\begin{array}{r}-0.90 \\
(0.562)\end{array}$ & $\begin{array}{r}*-4.38 \\
(0.080)\end{array}$ & -2.13 & $\begin{array}{c}0.05 \\
(0.953)\end{array}$ & ${ }^{*}-2.29$ \\
\hline GDPPC & $\begin{array}{r}* * *-0.47 \\
(0.001)\end{array}$ & $\begin{array}{r}* * *-0.56 \\
(0.000)\end{array}$ & $\begin{array}{r}* * * \\
(0.000)\end{array}$ & $\begin{array}{r}* * * \\
(0.000)\end{array}$ & $\begin{array}{r}* * *-0.45 \\
(0.001)\end{array}$ & $\begin{array}{r}* * * \\
-0.48 \\
(0.000)\end{array}$ \\
\hline $\mathrm{POP}$ & $\begin{array}{c}0.13 \\
(0.141)\end{array}$ & $\begin{array}{r}* * * \\
\quad 0.23 \\
(0.005)\end{array}$ & $\begin{array}{r}* 0.15 \\
(0.078)\end{array}$ & $\begin{array}{r}* 0.15 \\
(0.100)\end{array}$ & $\begin{array}{r}* * * \\
\quad 0.20 \\
(0.030)\end{array}$ & $\begin{array}{r}0.15 \\
(0.105)\end{array}$ \\
\hline OIL/DIAM & $\begin{array}{l}0.04 \\
(0.870)\end{array}$ & $\begin{array}{c}0.07 \\
(0.739)\end{array}$ & $\begin{array}{c}0.08 \\
(0.712)\end{array}$ & $\begin{array}{c}0.15 \\
(0.472)\end{array}$ & $\begin{array}{c}0.11 \\
(0.598)\end{array}$ & $\begin{array}{c}0.13 \\
(0.544)\end{array}$ \\
\hline MOUNT & $\begin{array}{c}0.01 \\
(0.136)\end{array}$ & $\begin{array}{c}0.01 \\
(0.162)\end{array}$ & $\begin{array}{c}0.00 \\
(0.344)\end{array}$ & $\begin{array}{r}* 0.01 \\
(0.058)\end{array}$ & $\begin{array}{l}* * 0.01 \\
(0.025)\end{array}$ & $\begin{array}{r}* * 0.01 \\
\quad(0.048)\end{array}$ \\
\hline NCONT & $\begin{array}{r}* * 0.85 \\
\quad(0.018)\end{array}$ & $\begin{array}{r}* * 0.82 \\
\quad(0.015)\end{array}$ & *** $\begin{array}{r}0.93 \\
(0.010)\end{array}$ & $\begin{array}{r}* * \\
\quad 0.72 \\
\quad(0.034)\end{array}$ & $\begin{array}{c}0.51 \\
(0.116)\end{array}$ & $\begin{array}{r}* * 0.72 \\
\quad(0.033)\end{array}$ \\
\hline DEMOC & $\begin{array}{r}-0.02 \\
(0.944)\end{array}$ & $\begin{array}{c}0.04 \\
(0.883)\end{array}$ & $\begin{array}{r}-0.01 \\
(0.977)\end{array}$ & $\begin{array}{c}0.03 \\
(0.906)\end{array}$ & $\begin{array}{c}0.10 \\
(0.703)\end{array}$ & $\begin{array}{c}0.01 \\
(0.977)\end{array}$ \\
\hline LAG & $\begin{array}{r}* * * \\
(0.000)\end{array}$ & $\begin{array}{r}* * * \\
(0.000)\end{array}$ & $\begin{array}{l}* * * \\
(0.000)\end{array}$ & $\begin{array}{c}* * * \\
(0.000)\end{array}$ & $\begin{array}{l}* * * \\
(0.000)\end{array}$ & ${ }^{* * *} \underset{(0.000)}{2.73}$ \\
\hline CONST & $\begin{array}{r}-1.49 \\
(0.322)\end{array}$ & $\begin{array}{r}*-2.75 \\
(0.053)\end{array}$ & $\begin{array}{r}-1.31 \\
(0.393)\end{array}$ & $\begin{array}{r}-1.42 \\
(0.379)\end{array}$ & $\begin{array}{r}-2.54 \\
(0.107)\end{array}$ & $\begin{array}{r}-1.50 \\
(0.345)\end{array}$ \\
\hline Pseu-R ${ }^{2}$ & 0.39 & 0.38 & 0.39 & 0.37 & 0.36 & 0.37 \\
\hline Obs & 1125 & 1125 & 1125 & 1117 & 1117 & 1117 \\
\hline$C$ & 138 & 138 & 138 & 137 & 137 & 137 \\
\hline Groups & Fearon & Fearon & Fearon & Eth & Eth & Eth \\
\hline
\end{tabular}

TABle 5. $P$ (with $\delta=0.05$ ) vs. $R$, Fearon and Ethnologue groupings.

Notes. $p$-values are reported in brackets. Robust standard errors adjusted for clustering have been employed to compute $z$-statistics.

The reason why $R$ might be problematic is simple. Ethnologue groupings are fully linguistic in nature. It is reasonable to presume that conflict in society did not follow every such linguistic division. Allowing this outcome to be modulated by a consideration of inter-group distances (even the linguistic "distances" that we adopt in the interest of exogeneity) helps enormously. Binary measures of polarization are too coarse to achieve this modulation in any meaningful way. The data fully support such an assertion.

5.4. Onset Versus Incidence. Our baseline specification uses incidence rather than onset, because the theory is silent on the initial decision to go to conflict. ${ }^{34}$ Moreover, the ${ }^{34}$ See Esteban and Ray (2007) for a two-stage model of conflict onset. 


\begin{tabular}{|c|c|c|c|c|c|c|}
\hline Variable & {$[1]$} & {$[2]$} & [3] & [4] & {$[5]$} & {$[6]$} \\
\hline$P$ & $\begin{array}{r}* * * 7.85 \\
(0.000)\end{array}$ & $\begin{array}{r}* * * * \\
(0.000)\end{array}$ & $\begin{array}{r}* * * 7.26 \\
\quad(0.000)\end{array}$ & $\begin{array}{r}* * * \\
(0.000)\end{array}$ & $\begin{array}{r}* * * \\
(0.000)\end{array}$ & *** $\begin{array}{r}8.71 \\
(0.000)\end{array}$ \\
\hline$F$ & $\begin{array}{r}* 0.94 \\
(0.050)\end{array}$ & $\begin{array}{c}0.72 \\
(0.139)\end{array}$ & $\begin{array}{c}0.62 \\
(0.204)\end{array}$ & $\begin{array}{c}0.39 \\
(0.336)\end{array}$ & $\begin{array}{c}0.20 \\
(0.602)\end{array}$ & $\begin{array}{c}0.15 \\
(0.702)\end{array}$ \\
\hline$G / N$ & $\begin{array}{r}* * *-10.19 \\
(0.002)\end{array}$ & $\begin{array}{r}* * *-8.44 \\
(0.004)\end{array}$ & $\begin{array}{r}* * *-8.23 \\
(0.007)\end{array}$ & $\begin{array}{r}* *-3.70 \\
(0.033)\end{array}$ & $\begin{array}{c}* *-3.92 \\
(0.026)\end{array}$ & $\begin{array}{r}* *-3.78 \\
(0.035)\end{array}$ \\
\hline GDPPC & $\begin{array}{r}* * * \\
-0.60 \\
(0.000)\end{array}$ & $\begin{array}{r}* * * \\
(0.000)\end{array}$ & $\begin{array}{r}* * * \\
(0.000)\end{array}$ & $\begin{array}{r}* * *-0.64 \\
(0.000)\end{array}$ & $\begin{array}{r}* * * \\
(0.7000)\end{array}$ & $\begin{array}{r}* * * \\
-0.73 \\
(0.000)\end{array}$ \\
\hline POP & $\begin{array}{c}0.01 \\
(0.863)\end{array}$ & $\begin{array}{c}0.03 \\
(0.711)\end{array}$ & $\begin{array}{c}0.03 \\
(0.748)\end{array}$ & $\begin{array}{c}0.06 \\
(0.493)\end{array}$ & & $\begin{array}{c}0.05 \\
(0.619)\end{array}$ \\
\hline OIL/DIAM & $\begin{array}{r}* * 0.54 \\
(0.016)\end{array}$ & $\begin{array}{c}* * \\
\quad 0.46 \\
(0.022)\end{array}$ & $\begin{array}{r}* * 0.47 \\
\quad(0.025)\end{array}$ & $\begin{array}{r}* * * \\
(0.004)\end{array}$ & $* * * \begin{array}{r}0.56 \\
(0.005)\end{array}$ & $\begin{array}{r}* * 0.57 \\
(0.007)\end{array}$ \\
\hline MOUNT & $\begin{array}{c}0.00 \\
(0.527)\end{array}$ & $\begin{array}{c}0.00 \\
(0.619)\end{array}$ & $\begin{array}{c}0.00 \\
(0.620)\end{array}$ & $\begin{array}{c}0.00 \\
(0.295)\end{array}$ & $\begin{array}{c}0.00 \\
(0.410)\end{array}$ & $\begin{array}{c}0.00 \\
(0.424)\end{array}$ \\
\hline NCONT & $\begin{array}{r}* * * 0.74 \\
\quad(0.005)\end{array}$ & $\begin{array}{r}* * 0.66 \\
\quad(0.010)\end{array}$ & $\begin{array}{c}0.42 \\
(0.104)\end{array}$ & $\begin{array}{r}* * 0.66 \\
\quad(0.012)\end{array}$ & $\begin{array}{r}* * 0.63 \\
(0.017)\end{array}$ & $\begin{array}{c}0.40 \\
(0.120)\end{array}$ \\
\hline DEMOC & $\begin{array}{r}-0.06 \\
(0.816)\end{array}$ & $\begin{array}{c}0.06 \\
(0.808)\end{array}$ & $\begin{array}{c}0.08 \\
(0.766)\end{array}$ & $\begin{array}{c}-0.02 \\
(0.936)\end{array}$ & $\begin{array}{c}0.09 \\
(0.716)\end{array}$ & $\begin{array}{c}0.10 \\
(0.704)\end{array}$ \\
\hline LAG & $\begin{array}{c}0.32 \\
(0.164)\end{array}$ & $\begin{array}{c}-0.08 \\
(0.740)\end{array}$ & $\begin{array}{r}-0.08 \\
(0.751)\end{array}$ & $\begin{array}{c}0.29 \\
(0.214)\end{array}$ & $\begin{array}{c}-0.13 \\
(0.618)\end{array}$ & $\begin{array}{r}-0.13 \\
(0.622)\end{array}$ \\
\hline CONST & $\begin{array}{l}1.67 \\
(0.310)\end{array}$ & $\begin{array}{l}1.74 \\
(0.269)\end{array}$ & $\begin{array}{c}2.04 \\
(0.199)\end{array}$ & $\begin{array}{l}1.27 \\
(0.448)\end{array}$ & $\begin{array}{l}1.93 \\
(0.227)\end{array}$ & $\begin{array}{c}2.19 \\
(0.173)\end{array}$ \\
\hline & 0.12 & 0.10 & 0.10 & 0.11 & 0.09 & 0.09 \\
\hline Groups & Fearon & Fearon & Fearon & Eth & Eth & Eth \\
\hline & 988 & 988 & 988 & 980 & 980 & 980 \\
\hline$C$ & 138 & 138 & 138 & 137 & 137 & 137 \\
\hline D. var. & ONSET 2 & ONSET 5 & ONSET8 & ONSET 2 & ONSET5 & ONSET 8 \\
\hline
\end{tabular}

TABLE 6. Conflict Onset, Fearon and Ethnologue groupings.

Notes. $p$-values are reported in brackets. Robust standard errors adjusted for clustering have been employed to compute $z$-statistics.

operational distinction between onset and conflict depends on taking the PRIO thresholds very seriously. Before the threshold is crossed, we might have several manifestations of serious conflict (a breakdown in negotiations, an insurgency, a crackdown). "Onset" as defined by the PRIO threshold is far from a sharp concept: it is arguably no different from a year of "incidence", though to be sure, the factors that contribute to the outbreak of a conflict do not coincide with the ones that keep feeding it (Schneider and Wiesehomeier, 2006). This is why we control for lagged conflict in our incidence regressions.

That said, in the interests of robustness, Table 6 provides some onset regressions. The binary onset variable ONSET $n$ switches on in a particular year if the incidence requirement 


\begin{tabular}{|c|c|c|c|c|c|c|c|}
\hline Variable & {$[1]$} & {$[2]$} & {$[3]$} & {$[4]$} & {$[5]$} & {$[6]$} & {$[7]$} \\
\hline$P$ & $\begin{array}{r}* * * 7.39 \\
(0.001)\end{array}$ & $\begin{array}{r}* * * 6.64 \\
(0.002)\end{array}$ & $\begin{array}{r}* * 5.36 \\
(0.034)\end{array}$ & $\begin{array}{r}* * * 7.24 \\
(0.001)\end{array}$ & $\begin{array}{r}* * * 9.56 \\
(0.001)\end{array}$ & $\begin{array}{r}* * * 7.39 \\
(0.001)\end{array}$ & 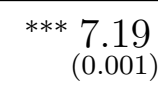 \\
\hline$F$ & ${ }^{* *} \begin{array}{l}1.30 \\
(0.012)\end{array}$ & $\begin{array}{r}* * * 2.03 \\
(0.001)\end{array}$ & $\begin{array}{r}* * * 2.74 \\
(0.001)\end{array}$ & ** $\begin{array}{c}1.28 \\
(0.030)\end{array}$ & *** $\begin{array}{c}1.49 \\
(0.009)\end{array}$ & ** $\begin{array}{c}1.33 \\
(0.012)\end{array}$ & *** $\begin{array}{r}1.76 \\
(0.001)\end{array}$ \\
\hline$G / N$ & $\begin{array}{r}*-4.80 \\
(0.068)\end{array}$ & $\begin{array}{r}* *-5.59 \\
(0.039)\end{array}$ & $\begin{array}{r}*-7.31 \\
(0.070)\end{array}$ & $\begin{array}{r}*-5.06 \\
(0.065)\end{array}$ & $\begin{array}{r}*-4.81 \\
(0.078)\end{array}$ & $\begin{array}{r}*-5.01 \\
(0.060)\end{array}$ & $\begin{array}{r}* *-6.09 \\
(0.032)\end{array}$ \\
\hline GDPPC & $\begin{array}{r}* * *-0.47 \\
(0.001)\end{array}$ & $\begin{array}{r}* * *-0.72 \\
(0.000)\end{array}$ & $\begin{array}{r}* * *-0.69 \\
(0.000)\end{array}$ & $\begin{array}{r}* *-0.39 \\
(0.024)\end{array}$ & $\begin{array}{r}* * *-0.45 \\
(0.006)\end{array}$ & $\begin{array}{r}* * *-0.49 \\
(0.001)\end{array}$ & ***- 0.60 \\
\hline POP & $\begin{array}{c}0.13 \\
(0.141)\end{array}$ & $\begin{array}{c}0.05 \\
(0.635)\end{array}$ & $\begin{array}{c}0.09 \\
(0.388)\end{array}$ & $\begin{array}{c}0.06 \\
(0.596)\end{array}$ & $\begin{array}{r}* 0.17 \\
(0.087)\end{array}$ & $\begin{array}{c}0.14 \\
(0.125)\end{array}$ & $\begin{array}{r}0.06 \\
(0.543)\end{array}$ \\
\hline OIL/DIAM & $\begin{array}{c}0.04 \\
(0.870)\end{array}$ & $\begin{array}{c}0.12 \\
(0.562)\end{array}$ & $\begin{array}{c}0.14 \\
(0.630)\end{array}$ & $\begin{array}{c}0.10 \\
(0.656)\end{array}$ & $\begin{array}{c}0.10 \\
(0.687)\end{array}$ & $\begin{array}{c}0.05 \\
(0.824)\end{array}$ & $\begin{array}{c}0.15 \\
(0.476)\end{array}$ \\
\hline MOUNT & $\begin{array}{c}0.01 \\
(0.136)\end{array}$ & $\begin{array}{c}0.00 \\
(0.331)\end{array}$ & $\begin{array}{r}-0.00 \\
(0.512)\end{array}$ & $\begin{array}{c}0.01 \\
(0.114)\end{array}$ & $\begin{array}{r}* * 0.01 \\
\quad(0.038)\end{array}$ & $\begin{array}{c}0.01 \\
(0.109)\end{array}$ & $\begin{array}{c}0.01 \\
(0.212)\end{array}$ \\
\hline NCONT & $\begin{array}{r}* * 0.85 \\
(0.018)\end{array}$ & $\begin{array}{r}* * 0.87 \\
(0.018)\end{array}$ & $\begin{array}{l}* 0.75 \\
(0.064)\end{array}$ & $\begin{array}{r}* * 0.83 \\
(0.039)\end{array}$ & $\begin{array}{c}0.62 \\
(0.134)\end{array}$ & ** 0.82 & $\begin{array}{r}* * 0.77 \\
(0.040)\end{array}$ \\
\hline DEMOC & $\begin{array}{r}-0.02 \\
(0.944)\end{array}$ & $\begin{array}{c}0.08 \\
(0.761)\end{array}$ & $\begin{array}{c}-0.03 \\
(0.932)\end{array}$ & $\begin{array}{r}-0.23 \\
(0.389)\end{array}$ & $\begin{array}{c}0.10 \\
(0.716)\end{array}$ & $\begin{array}{c}0.08 \\
(0.750)\end{array}$ & $\begin{array}{c}0.13 \\
(0.621)\end{array}$ \\
\hline LAG & *** $\begin{array}{r}2.73 \\
(0.000)\end{array}$ & *** $\begin{array}{l}2.68 \\
(0.000)\end{array}$ & *** 2.83 & $\begin{array}{r}* * * 2.69 \\
(0.000)\end{array}$ & *** 2.92 & $\begin{array}{r}* * * 2.79 \\
(0.000)\end{array}$ & *** $\begin{array}{r}2.74 \\
(0.000)\end{array}$ \\
\hline CONST & -1.49 & $\begin{array}{c}1.91 \\
(0.324)\end{array}$ & $\begin{array}{c}0.86 \\
(0.708)\end{array}$ & $\begin{array}{c}0.95 \\
(0.557)\end{array}$ & -2.68 & $\begin{array}{c}-2.03 \\
(0.199)\end{array}$ & $\begin{array}{c}0.69 \\
(0.681)\end{array}$ \\
\hline Pseu-R ${ }^{2}$ & 0.39 & 0.39 & 0.44 & 0.35 & 0.43 & 0.39 & 0.39 \\
\hline Reg/Time & none & reg.dum. & no Afr & no Asia & no L.Am. & trend & interac. \\
\hline Obs & 1125 & 1125 & 779 & 963 & 936 & 1125 & 1125 \\
\hline$C$ & 138 & 138 & 98 & 117 & 117 & 138 & 138 \\
\hline
\end{tabular}

TABLE 7. Region and Time Effects, Fearon groupings.

Sources and Notes. PRIO25 throughout. $p$-values are reported in brackets. Robust standard errors adjusted for clustering have been employed to compute $z$-statistics.

is met (at the level of PRIO25), but not in $n$ or more previous years. ${ }^{35}$ We take three definitions of onset by setting $n=2,5,8 .{ }^{36}$ The first three columns report onset for Fearon groupings. The next three do the same for Ethnologue groupings. ${ }^{37}$

It is clear that nothing of importance changes in the results. In each of the specifications, polarization is positive and (usually) highly significant. Fractionalization and the Greenberg-Gini continue to be generally significant, though not as strongly.

\footnotetext{
${ }^{35}$ See Strand (2006) for the PRIO based dataset on conflict onset.

${ }^{36}$ Note that if one adopts a more strict notion of conflict, such as PRIO1000, peace becomes a looser concept.

${ }^{37}$ To maintain symmetry, we carry lagged dependent variables in these regressions as well. Not much is achieved thereby, in contrast to the case of conflict incidence. The variables are insignificant, and their inclusion or exclusion makes no difference.
} 
5.5. Region and Time Effects. We check whether the results are driven by particular regions which might be considered more (or less) conflictual. Table 7 reports on the findings. Column 1 is just the baseline specification for easy comparison. Column 2 introduces regional dummies. Columns 3-5 eliminates a region each: Africa, Asia and Latin America, in that order. Column 6 returns to the baseline but this time with a full set of overall time dummies, one for each period in the sample except for the first one. Column 7 controls for possibly different regional time trends. To this effect, we introduce regional dummies interacted with a time trend.

It appears that the significance of polarization, overwhelmingly at around the $1 \%$ level, is unshakeable. Fractionalization is positive and significant as well, often highly so. The Greenberg-Gini coefficient is significant and it continues to have the ubiquitous negative sign.

5.6. Alternative Estimation Strategies. Table 8 summarizes other ways of estimating the conflict equation. To facilitate comparison, Column 1 recalls the baseline specification in Column 6 of Table 1. Column 2 presents estimates obtained in a pure cross sectional regression. In this case, the dependent variable is the average over the 1960-2008 period of PRIO25, while data on all time-dependent variables come from 1960. Column 3 estimates our baseline specification using annual data in Fearon (2005). ${ }^{38}$ Column 4 uses rare events estimation to correct for the bias created in a logit model for the small number of conflict observations relative to the total, as in King and Zeng (2001). Column 5 presents the same results as Column 1 using the linear probability model. Finally, Column 6 uses a linear specification and allows for the possibility that the distributional coefficients for each country are random draws from a probability distribution, while the other coefficients are held fixed as before. We return to this particular specification in the next section.

It is fair to say that in the variations we study (and in others not reported here), our conclusions are unaltered. The coefficients of $F$ and $P$ are generally positive and highly significant. The variable $G / N$ is negative and sometimes significant. Our overall interpretation of these results, as discussed in the baseline specification, remains unchanged.

\footnotetext{
${ }^{38}$ Fearon's sample runs from 1960 to 1999. Since annual data on democracy is not available in this sample, its value in the first five-year period, 1960-1965, has been used instead.
} 


\begin{tabular}{|c|c|c|c|c|c|c|}
\hline Variable & [1] & {$[2]$} & [3] & [4] & [5] & {$[6]$} \\
\hline$P$ & 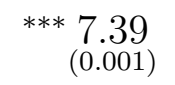 & *** $\begin{array}{r}11.84 \\
(0.003)\end{array}$ & $\begin{array}{r}* * 4.68 \\
\quad(0.015)\end{array}$ & $\begin{array}{r}* * * 7.13 \\
\quad(0.000)\end{array}$ & $\begin{array}{r}* * * \\
\quad 0.86 \\
(0.004)\end{array}$ & $\begin{array}{rl}* * * & 0.95 \\
& (0.001)\end{array}$ \\
\hline$F$ & ** 1.30 & *** 2.92 & *** 1.32 & ${ }^{* * *} \frac{1.27}{(0.005)}$ & $\begin{array}{r}* * 0.13 \\
(0.025)\end{array}$ & $* * * \begin{array}{r}0.16 \\
(0.008)\end{array}$ \\
\hline$G / N$ & $\begin{array}{c}* 4.80 \\
(0.068)\end{array}$ & $\begin{array}{r}-5.53 \\
(0.136)\end{array}$ & $\begin{array}{c}-3.54 \\
(0.133)\end{array}$ & $\begin{array}{r}-4.12 \\
(0.192)\end{array}$ & $\begin{array}{c}*-0.16 \\
(0.061)\end{array}$ & $\begin{array}{r}-0.17 \\
(0.286)\end{array}$ \\
\hline GDPPC & $\begin{array}{r}* * * \\
(0.47)\end{array}$ & $* * *-0.77$ & ${ }^{* *}-0.29$ & $\begin{array}{r}* * * \\
(0.000)\end{array}$ & $\begin{array}{r}* * *-0.05 \\
(0.000)\end{array}$ & $\begin{array}{r}* * * \\
(0.000)\end{array}$ \\
\hline POP & $\begin{array}{c}0.13 \\
(0.141)\end{array}$ & $\begin{array}{c}0.03 \\
(0.858)\end{array}$ & $\begin{array}{c}0.14 \\
(0.123)\end{array}$ & $\begin{array}{rl}* * & 0.14 \\
(0.090)\end{array}$ & $\begin{array}{r}* * 0.02 \\
\quad(0.020)\end{array}$ & $\begin{array}{rl}* * & 0.02 \\
& (0.032)\end{array}$ \\
\hline OIL/DIAM & $\begin{array}{c}0.04 \\
(0.870)\end{array}$ & $\begin{array}{r}* * 0.94 \\
(0.028)\end{array}$ & $\begin{array}{c}0.29 \\
(0.280)\end{array}$ & $\begin{array}{c}0.04 \\
(0.850)\end{array}$ & $\begin{array}{c}0.00 \\
(0.847)\end{array}$ & $\begin{array}{c}0.01 \\
(0.682)\end{array}$ \\
\hline MOUNT & $\begin{array}{c}0.01 \\
(0.136)\end{array}$ & $\begin{array}{c}0.01 \\
(0.102)\end{array}$ & $\begin{array}{c}0.00 \\
(0.510)\end{array}$ & $\begin{array}{c}0.01 \\
(0.185)\end{array}$ & $\begin{array}{c}0.00 \\
(0.101)\end{array}$ & $\begin{array}{c}0.00 \\
(0.179)\end{array}$ \\
\hline NCONT & ** $\begin{array}{c}0.85 \\
(0.018)\end{array}$ & *** $\frac{1.51}{(0.007)}$ & $\begin{array}{l}* 0.62 \\
(0.052)\end{array}$ & $\begin{array}{c}* * * \begin{array}{c}0.83 \\
(0.002)\end{array}\end{array}$ & $\begin{array}{c}* * \\
0.09 \\
(0.019)\end{array}$ & $\begin{array}{l}* * * \\
\quad 0.10 \\
(0.006)\end{array}$ \\
\hline DEMOC & $\begin{array}{r}-0.02 \\
(0.944)\end{array}$ & $\begin{array}{r}-0.48 \\
(0.212)\end{array}$ & $\begin{array}{c}-0.09 \\
(0.690)\end{array}$ & $\begin{array}{r}-0.02 \\
(0.941)\end{array}$ & $\begin{array}{c}0.01 \\
(0.788)\end{array}$ & $\begin{array}{c}0.01 \\
(0.585)\end{array}$ \\
\hline LAG & $\begin{array}{r}* * * 2.73 \\
(0.000)\end{array}$ & - & $\begin{array}{rl}* * * & 4.69 \\
& (0.000)\end{array}$ & $\begin{array}{r}* * * 2.69 \\
(0.000)\end{array}$ & $\begin{array}{r}* * * 0.54 \\
(0.000)\end{array}$ & $\begin{array}{r}* * * \\
0.45 \\
(0.000)\end{array}$ \\
\hline CONST & $\begin{array}{c}-1.49 \\
(0.322)\end{array}$ & - & ${ }^{* *}-\underset{(0.027)}{2.23}$ & $\begin{array}{r}-1.62 \\
(0.322)\end{array}$ & $\begin{array}{c}0.10 \\
(0.514)\end{array}$ & $\begin{array}{c}0.18 \\
(0.361)\end{array}$ \\
\hline$\left(\right.$ I seu $\left.^{-}\right) \mathrm{n}$ & 0.39 & 0.13 & 0.60 & - & 0.44 & \\
\hline Method & Logit & OLogit(CS) & $\operatorname{Logit}(Y)$ & ReLogit & OLS & $\mathrm{RC}$ \\
\hline Obs & 1125 & 136 & 4429 & 1125 & 1125 & 1125 \\
\hline$C$ & 138 & 136 & 131 & 138 & 138 & 138 \\
\hline
\end{tabular}

TABLE 8. Alternative estimation strategies, Fearon groupings.

Notes. PRIO25 and $\delta=0.05$ throughout. $p$-values are reported in brackets. Robust standard errors adjusted for clustering have been employed to compute $z$-statistics. OLogit(CS): cross-sectional data estimated using ordered logit. Logit(Y): yearly data estimated using Logit. ReLogit: Rare Events Logit estimator. OLS: Ordinary Least Squares in a LPM. RC: Random coefficients in a LPM.

\section{Inter-Country Variations in Publicness, Privateness, and Cohesion}

An important insight of equation (2) is that the effect of each distributional measure is influenced in specific ways by the relative publicness of conflict payoffs, as well as the extent of group cohesion. Recall (2), and note that $\lambda \equiv \pi /(\pi+\mu)$ measures the "relative publicness" of the prize. Observe that the impact of $P$ is enhanced by $\lambda$, and that of $F$ by $(1-\lambda)$. In particular, when all conflicts are public, fractionalization cannot matter, while if all conflicts are private, polarization cannot matter. But the presence of group cohesion strengthens both these variables; consult (2). 
While we've discussed this interpretation using the baseline specification, it isn't hard to imagine that relative publicness is country-specific, and so is the extent of group cohesion. That places stress on the cross-country specification so far, which presumes — the presence of additive controls notwithstanding - that the coefficients on the distributional variables are independent of country. The random-coefficients specification in the very last column of Table 8 is of particular interest here. Using a likelihood ratio test, we can indeed reject the hypothesis of constant coefficients. Statistically, this is no surprise, as such a specification across countries is often rejected anyway, though we return to this test below. ${ }^{39}$ Despite this, it is of interest that the estimates of the coefficients in the OLS-LPM and RC specifications (see columns 5 and 6 of Table 8) are very similar - these coefficients are comparable since they've both been estimated in a linear specification. That suggests that the qualitative and quantitative conclusions of the first part of the paper hold when the assumption of constancy of the coefficients is dropped.

The goal of this section, then, is to construct and use country-by-country proxies for relative publicness and cohesion.

We first construct indicators for $\pi$ and $\mu$, and use these to define a proxy for the relative publicness of the prize. Begin with the indicator for the private payoff $\mu$. It seems natural to associate $\mu$ with rents that are easily appropriable. Because appropriability is closely connected to the presence of resources, we approximate the degree of "privateness" in the prize by asking if the country is rich in natural resources. We proxy the abundance of natural resources by the per capita value of oil reserves (OILRESV). ${ }^{40}$ Next, we create an index of "publicness", PUB, by asking different questions about the degree of power afforded to those who run the country, "more democratic" being regarded as correlated with "less power" and consequently a lower valuation of the public payoff to conflict. We

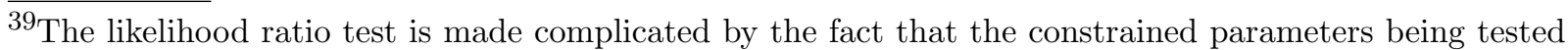
- the variances of the random coefficients equal zero - lie on the boundary of the parameter space. A general distribution theory for this test is not available, but Stram and Lee (1994) show that the tail probabilities of the distribution of our test statistic are bounded above by those of the $\chi^{2}$ with the standard degrees of freedom, four in our case. The test thus provides a sufficient condition for rejection using the $\chi^{2}(4)$ distribution.

${ }^{40}$ Data for oil reserves comes from Haber and Menaldo (2011). See the Appendix for details on the construction of this variable.
} 


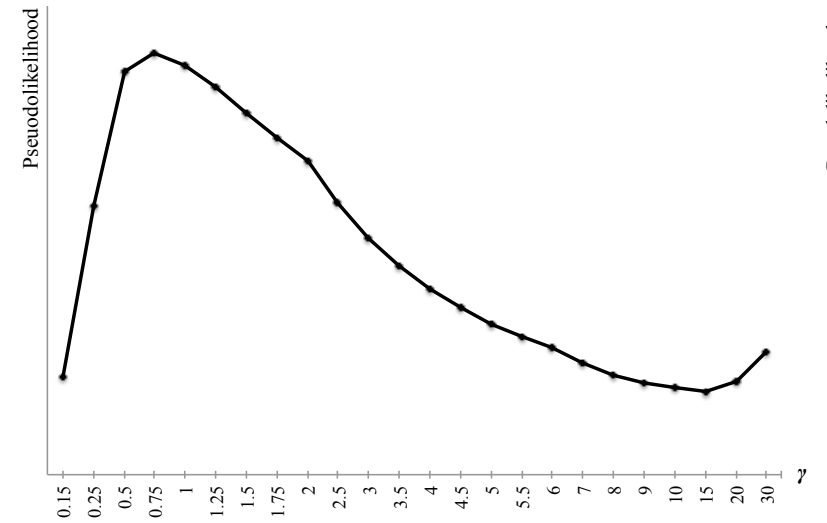

(A) Without Group Cohesion

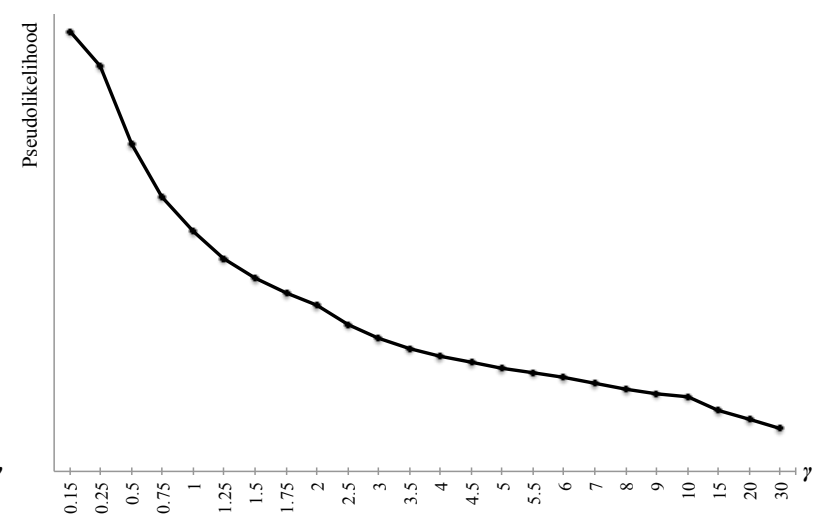

(B) With Group Cohesion

Figure 3. Pseudolikelihoods For Different VAlues of $\gamma$.

use four different proxies to construct the index: ${ }^{41}$ (i) the lack of executive constraints (EXCONS), (ii) the level of autocracy (AUTOCR), (iii) the degree to which political rights are flouted (POLRIGHTS), and (iii) the extent of suppression of civil liberties (CIVLIB). Our variable PUB is constructed by looking at binary versions of these outcomes and then averaging the indicators. Details are in the Appendix. The results are robust to different modes of construction and indeed to the choice of a subset of these measures; see the online Appendix for some variants.

Our proxy for the relative publicness of the prize is given by

$$
\Lambda(\gamma) \equiv\left(\gamma \mathrm{PUB}^{*} \mathrm{GDP}\right) /\left(\gamma \mathrm{PUB}^{*} \mathrm{GDP}+\text { OILRESV }\right)
$$

where we multiply the PUB indicator by per-capita GDP to convert the "poor governance" variables into monetary equivalents (note that oil reserves are expressed in money values per capita as well). The "conversion factor" $\gamma$ makes the privateness and publicness variables comparable, and allows us to combine them to arrive at the ratio $\Lambda(\gamma)$.

We take $\gamma=1$ in the main text. The online Appendix shows that the results are robust to a wide range of values of $\gamma$. In addition, we can compute pseudo-likelihoods for different values of $\gamma$, just as we did for the linguistic distance coefficient (see Figure 2). Figure 3 displays the likelihood results for the dependent variable PRIO25, and for the two

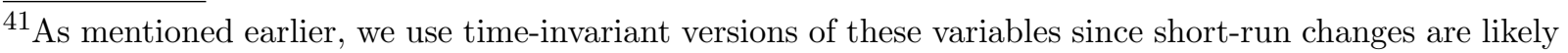
to be correlated with the incidence of conflict.
} 


\begin{tabular}{|c|c|c|c|c|c|c|}
\hline Variable & {$[1]$} & {$[2]$} & {$[3]$} & {$[4]$} & {$[5]$} & {$[6]$} \\
\hline$P$ & $\begin{array}{r}-3.31 \\
(0.424)\end{array}$ & $\begin{array}{l}-1.93 \\
(0.538)\end{array}$ & $\begin{array}{l}-9.21 \\
(0.561)\end{array}$ & $\begin{array}{r}-3.01 \\
(0.478)\end{array}$ & $\begin{array}{l}-1.65 \\
(0.630)\end{array}$ & $\begin{array}{r}-13.04 \\
(0.584)\end{array}$ \\
\hline$F$ & $\begin{array}{c}0.73 \\
(0.209)\end{array}$ & $\begin{array}{c}0.75 \\
(0.157)\end{array}$ & $\begin{array}{l}-2.27 \\
(0.249)\end{array}$ & $\begin{array}{c}1.48 \\
(0.131)\end{array}$ & $\begin{array}{l}1.51 \\
(0.108)\end{array}$ & $* *-6.65$ \\
\hline$G / N$ & $\begin{array}{r}-5.07 \\
(0.346)\end{array}$ & $\begin{array}{r}-4.61 \\
(0.352)\end{array}$ & $\begin{array}{c}0.78 \\
(0.789)\end{array}$ & $\begin{array}{r}-3.78 \\
(0.767)\end{array}$ & $\begin{array}{l}3.31 \\
(0.742)\end{array}$ & $\begin{array}{r}-71.03 \\
(0.214)\end{array}$ \\
\hline$P \Lambda$ & $\begin{array}{r}* * * 17.38 \\
(0.001)\end{array}$ & $\begin{array}{r}* * *+13.53 \\
(0.001)\end{array}$ & $\begin{array}{r}* * * 60.23 \\
(0.005)\end{array}$ & & & \\
\hline$F(1-\Lambda)$ & $\begin{array}{rl}* * * & 2.53 \\
(0.003)\end{array}$ & *** 1.92 & $\begin{array}{r}* * * 11.87 \\
(0.000)\end{array}$ & & & \\
\hline$(G / N) \Lambda$ & $\begin{array}{r}-0.72 \\
(0.912)\end{array}$ & $\begin{array}{r}-1.37 \\
(0.823)\end{array}$ & $\begin{array}{r}-9.57 \\
(0.298)\end{array}$ & & & \\
\hline$P \Lambda A$ & & & & $\begin{array}{r}* * 23.25 \\
(0.021)\end{array}$ & $\begin{array}{r}* * \\
\text { (0.019) }\end{array}$ & $\begin{array}{r}* 72.22 \\
(0.083)\end{array}$ \\
\hline$F(1-\Lambda) A$ & & & & $\begin{array}{rl}* * & 4.02 \\
(0.013)\end{array}$ & *** 2.92 & $\begin{array}{r}* * * * 26.03 \\
(0.000)\end{array}$ \\
\hline$(G / N) \Lambda(1-A)$ & & & & -2.31 & $\begin{array}{r}-68.42 \\
(0.358)\end{array}$ & $\begin{array}{c}* 579.24 \\
(0.089)\end{array}$ \\
\hline GDPPC & $\begin{array}{r}* * *-0.62 \\
(0.000)\end{array}$ & $\begin{array}{r}* * *-0.50 \\
(0.000)\end{array}$ & $\begin{array}{l}* * * \\
(0.000)\end{array}$ & $* * *-0.65$ & $\begin{array}{r}* * * \\
(0.003)\end{array}$ & $\begin{array}{r}* * *-3.68 \\
(0.000)\end{array}$ \\
\hline POP & $\begin{array}{l}0.10 \\
(0.267)\end{array}$ & $\begin{array}{c}0.09 \\
(0.243)\end{array}$ & $\begin{array}{l}* * * \\
(0.900)\end{array}$ & $\begin{array}{c}0.08 \\
(0.622)\end{array}$ & $\begin{array}{c}0.09 \\
(0.448)\end{array}$ & $\begin{array}{c}0.33 \\
(0.565)\end{array}$ \\
\hline OILRESV & $\begin{array}{r}-0.00 \\
(0.986)\end{array}$ & $\begin{array}{c}0.00 \\
(0.860)\end{array}$ & $\begin{array}{c}0.00 \\
(0.277)\end{array}$ & ** 0.00 & $\begin{array}{ll}* * * & 0.00 \\
(0.006)\end{array}$ & $\begin{array}{l}0.00 \\
(0.234)\end{array}$ \\
\hline MOUNT & $\begin{array}{rl}* & 0.01 \\
(0.059)\end{array}$ & $\begin{array}{c}0.00 \\
(0.169)\end{array}$ & $\begin{array}{r}* * 0.04 \\
(0.012)\end{array}$ & $\begin{array}{l}* * * 0.02 \\
\quad(0.009)\end{array}$ & $\begin{array}{l}* * \\
\text { * }\end{array}$ & $\begin{array}{r}* * 0.06 \\
(0.032)\end{array}$ \\
\hline NCONT & ** $\begin{array}{r}0.87 \\
(0.015)\end{array}$ & $\begin{array}{c}0.41 \\
(0.173)\end{array}$ & $\begin{array}{l}* * * 4 \\
\quad 4.21 \\
\quad(0.005)\end{array}$ & $\begin{array}{rl}* * * & 1.31 \\
(0.002)\end{array}$ & $\begin{array}{l}* * * 0.93 \\
\quad(0.007)\end{array}$ & $\begin{array}{rl}* * * & 4.98 \\
(0.008)\end{array}$ \\
\hline PUBGDPPC & $\begin{array}{c}0.00 \\
(0.397)\end{array}$ & $\begin{array}{c}0.00 \\
(0.847)\end{array}$ & $\begin{array}{r}* *_{-}-0.00 \\
(0.014)\end{array}$ & $\begin{array}{r}* * 0.00 \\
(0.024)\end{array}$ & $\begin{array}{r}* 0.00 \\
\quad(0.074)\end{array}$ & $\begin{array}{r}-0.00 \\
(0.214)\end{array}$ \\
\hline LAG & $* * * 2.62$ & *** 1.93 & $\begin{array}{r}* * * \\
0.47 \\
(0.000)\end{array}$ & *** 2.40 & *** $\begin{array}{c}1.79 \\
(0.000)\end{array}$ & *** 0.42 \\
\hline CONST & $\begin{array}{r}-0.01 \\
(0.995)\end{array}$ & - & $\begin{array}{c}5.27 \\
(0.354)\end{array}$ & $\begin{array}{r}-0.43 \\
(0.900)\end{array}$ & - & $\begin{array}{r}* 28.33 \\
(0.072)\end{array}$ \\
\hline$\left(\right.$ Pseu-) $R^{2}$ & 0.40 & 0.34 & 0.42 & 0.48 & 0.39 & 0.41 \\
\hline Obs & 1104 & 1104 & 1090 & 447 & 447 & 443 \\
\hline C & 138 & 138 & 138 & 53 & 53 & 53 \\
\hline D. var. & PRIO25 & PRIO-INT & ISC & PRIO25 & PRIO-INT & ISC \\
\hline
\end{tabular}

TABLE 9. Relative publicness and cohesion, Fearon groupings.

Notes. $p$-values are reported in brackets. Robust standard errors adjusted for clustering have been employed to compute $z$-statistics.

empirical specifications in Table 9 that use PRIO25. Clearly, $\gamma=1$ is a good choice under this criterion.

Table 9, columns 1-3, provides a variety of different specifications using the binary variable PRIO25 as well as the multivalued indicators PRIOINT and ISC. Group cohesion is 
held constant, and our main independent variables are $P * \Lambda, F *(1-\Lambda)$, and $G / N * \Lambda$, where $\Lambda \equiv \Lambda(1)$. This allows to test whether the interacted indices of ethnic inequality, fractionalization and polarization are significant. We also include the noninteracted indices in order to examine whether their significance truly comes from the interaction term. ${ }^{42}$ Polarization interacted with $\Lambda$ is positive and generally significant, and the same is true of fractionalization interacted with $1-\Lambda$. (The interacted Greenberg-Gini is not significant.)

The level terms $P, F$ and $G$ are now no longer significant. Conditional on having the true values of $\lambda$, this is precisely what the model would predict. After all, the influence of polarization (say) should be zero when there are no public goods, broadly defined to include primordial goals, at stake. The fact that our estimate $\Lambda$ happens to achieve the same goal is of interest, and possibly suggests that factors such as pure primordialism have little to do with ethnic conflict.

We remark on the interpretation of interactions in nonlinear regressions (such as the logit). It is well known that any significance of an interaction term cannot be attributed fully to the true effect of that interaction term on the dependent variable (see, e.g., Ai and Norton (2003)). ${ }^{43}$ However, it does imply that the effect on the underlying latent variable - the cost of conflict, as proxied by the number of deaths - is indeed as estimated. And this is what we are interested in from the viewpoint of the theory.

Next, we allow group cohesion to vary across countries. We estimate a proxy $A$ for the level of group cohesion $\alpha$ by exploiting the answers to a certain set of questions asked in the 2005 wave of the World Values Survey. We use the latest wave available because it covers the largest number of countries. One could argue that the answers might be conditioned by the existence of previous or contemporary conflict. The questions we have selected, described in detail in the Appendix, do not ask about specific groups, but address issues like adherence to social norms, identification with the local community, the importance of

\footnotetext{
${ }^{42}$ We do not include the level of $\Lambda$ - there is nothing to suggest that it will have a level effect — but rather the components of $\Lambda$, which are the OILRESV indicator and the variable PUB* GDP constructed from the governance variables.

${ }^{43} \mathrm{~A}$ linear probability model, though problematic on other grounds, would not exhibit this problem.
} 
helping others, and so on. ${ }^{44}$ We construct a summary proxy for $\alpha$ - call it $A$ - from the scores on these questions.

Unfortunately, a significant shortcoming of this approach is that the sample of countries even in the 2005 World Values Survey is limited. We are therefore restricted to only 447 observations, corresponding to 53 countries.

Columns 4-6 of Table 9 examine this variant. In this specification the independent variables are exactly the ones posited by the model. We use precisely the combinations asked for by the theory: polarization is weighted both by $\Lambda$ and by $A$, fractionalization by $(1-\Lambda)$ and by $A$ again, and so on. We continue to employ the direct terms $P, F$ and $G$, as well as the controls. ${ }^{45}$ The results continue to be quite striking. The composite terms for polarization and fractionalization are significant. The levels continue to be insignificant.

Finally, we test the hypothesis that now, with the interacted effects in place, the estimated coefficients can be taken to be common across countries. We re-estimate the regressions in Table 9 by allowing for random coefficients in the interacted and noninteracted indices. This time, invoking the Stram-Lee test once again, we are unable to reject the null hypothesis of constant coefficients for columns 3 to $6 .^{46}$ This is by no means conclusive, but it suggests that a fair amount of inter-country variation is indeed being picked up by the new specifications of Table 9 .

We remind the reader that we have reported our results using the conversion factor $\gamma=1$ to aggregate public and private prizes in equation (5). The online Appendix reports on several versions of Table 9 , for different values of $\gamma$, and shows that our results are robust to these variations.

\section{Summary and Conclusions}

In a monumental treatise, Donald Horowitz (1985) observes of the second half of the twentieth century that

\footnotetext{
${ }^{44}$ To be sure, even such a procedure is vulnerable to charges of endogeneity, but hopefully less so.

${ }^{45}$ We feel no particular compunction to include all possible level effects. Terms such as $P * \Lambda * A$ can be viewed as composite variables that the model predicts will matter, and not as interactions of (in this instance) three variables.

${ }^{46}$ See Table 15 in the online Appendix and the discussion there.
} 
"In much of Asia and Africa, it is only modest hyperbole to assert that the Marxian prophecy has had an ethnic fulfillment."

This is a remarkable assertion. The fundamental question of interest is whether ethnic "divisions" do matter for social conflict. We've argued that such a question cannot be properly addressed unless we have theory to guide us on the empirical construction of an "ethnic division". As Esteban and Ray (2011) show, the appropriate choice of division depends on the nature of the conflict - whether it is over public or private goods - and the extent of cohesion within the groups that are engaged in conflict. In particular, that paper links ethnic conflict to a linear combination of ethnic polarization, ethnic fractionalization and the Greenberg-Gini index of inter-group differences. As we have discussed in some detail in the paper, the weights in that linear combination correspond to the relative importance of public and private goods in the conflict prize. Specifically, the impact of polarization increases with conflict over public goods, while the impact of fractionalization increases with the private component of conflict. The Esteban-Ray framework also tells us that the importance of the three indices depends on the extent of within-group cohesion present in inter-group conflict. (In particular, when there is no cohesion at all, the wellknown free-rider problem dominates and all conflict vanishes when the population is large.) The theoretical structure therefore both disciplines our empirical specification and allows for interpretation of the estimated coefficients.

The first task of this paper is to implement the above measures; specifically, those that employ inter-group "distances". We do so using linguistic differences across groups, in the spirit of Fearon (2003) and Desmet et al. (2009). Linguistic distance - as constructed by the cardinality of intervening nodes on the language tree - is plausibly exogenous to conflict, while at the same time they can be expected to drive — or at least influence antagonisms across groups. ${ }^{47}$

\footnotetext{
${ }^{47}$ Another possibility, infeasible at present, is to use measures of genetic distance across groups. This is not hard to do across countries, but at this time there is too little within-country variation. In those cases in which more disaggregated data is available (see Cavalli-Sforza et al. (1994)), it has been prohibitively difficult to obtain group share data. Perhaps in the near future, with more detailed genetic datasets, this approach will become feasible.
} 
We then proceed to an empirical analysis that closely parallels the theory. Our main result is that ethnic polarization has a large and highly significant impact on conflict across a number of different specifications. By and large, though with somewhat lesser consistency, this is also true of fractionalization. These two findings suggest that public and private components of conflict are generally both present, and that within-group cohesion is strong during conflict. ${ }^{48}$ The numerical effects of the two measures are large and quite similar. For instance, moving polarization from the 20th percentile to the 80th percentile, holding all other variables at their means, approximately doubles the chances of conflict, and the same is true of fractionalization.

Our results concerning polarization (and to a lesser degree, fractionalization) are highly robust. They extend to a variety of different measures of conflicts (including different binary measures of conflict incidence, as well as continuous indices), to alternative ways of calculating language distances, to different choices of groups (as long as language is principally used in defining them), to the use of different regional dummies or selections, and to the inclusion of overall or regional time trends.

A limitation of our cross-sectional approach is that the importance of public and private components of conflict, as well as the extent of group cohesion, are presumed not to vary over countries. We therefore pursue refinements of our specification by constructing country-specific measures of "relative publicness" of the prize, using data on natural resources (as a proxy for private payoffs) and data on autocracy (as a proxy for public payoff to holding power). We combine these measures to create an index of "relative publicness" of conflict payoffs, one that varies across countries. When our measures are interacted with this index in exactly the way suggested by the theory, the resulting coefficients are significant across a variety of specifications, and are strongly supportive of the conceptual framework

\footnotetext{
${ }^{48}$ The Greenberg-Gini index (normalized by population, as required by the theory) is also significant in several of the specifications, but usually with a negative sign. This finding supports our conclusion that group cohesion is extremely important and present to a significant degree in times of conflict. Presumably, the very fact that a conflict is observed implies that free-rider problems have been overcome to a large extent.
} 
The exercise can be augmented still further by using a measure for within-group cohesion, one that we construct by using information from the World Values Survey. We can then directly address the model by imposing even more structure, by constructing variables that conform precisely to those predicted by the theory. The resulting outcomes, both for polarization and fractionalization, are highly significant.

This paper takes a step towards the establishment of a strong empirical relationship between conflict and certain indicators of ethnic group distribution, one that is firmly grounded in theory. Observe that in no case do we use income-based groups or incomebased measures, and in this sense our study is perfectly orthogonal to those that attempt to find a relationship between economic inequality and conflict. At the same time, as we have argued in this paper, this is not to say that conflict is fundamentally non-economic. It could be. But there is an equal possibility that the economics of conflict finds expression across groups that are demarcated on other grounds: religion, caste, geography or language. Such markers can profitably be exploited for economic and political ends, even when the markers themselves have nothing to do with economics. However, a more nuanced study of the relative importance of economic versus primordial antagonisms must await future research.

\section{REFERENCES}

Ai, C. and E. Norton (2003) "Interaction terms in logit and probit models," Economics Letters 80, 123-129.

Alesina, A., A. Devleeschauwer, W. Easterly, S. Kurlat and R. Wacziarg (2003) "Fractionalization," Journal of Economic Growth 8, 155-194.

Banks, A. S. (2008) "Cross-National Time-Series Data Archive (CNTS) 1815-2007," Databanks International, Jerusalem, Israel.

Besley, T. and T. Persson (2011) "State Capacity, Conflict, and Development" Econometrica $78,134$.

Blattman, C. and E. Miguel (2010) "Civil War", Journal of Economic Literature 48, 3-57. Brockett, C. D. (1992) "Measuring Political Violence and Land Inequality in Central America," American Political Science Review 86, 169-176. 
Collier, P. and A. Hoeffler (2002) "On the Incidence of Civil War in Africa," Journal of Conflict Resolution 46, 13-28.

Collier, P. and A. Hoeffler (2004) "Greed and Grievance in Civil War," Oxford Economics Papers 56, 563-595.

Collier, P., A. Hoeffler, and D. Rohner (2009) "Beyond Greed and Grievance: Feasibility and Civil War," Oxford Economics Papers 61, 1-27.

Desmet, K., I. Ortuño-Ortín, and R. Wacziarg (2009) "The Political Economy of Ethnolinguistic Cleavages," NBER, wp n. 15360.

Desmet, K., I. Ortuño-Ortín, and S. Weber (2010) "Linguistic Diversity and Redistribution", Journal of the European Economic Association 7, 1291-1318.

Doyle, M. and N. Sambanis (2000) "International Peacebuilding: A Theoretical and Quantitative Analysis," American Political Science Review 94, 779-801.

Easterly W. and R. Levine (1997) "Africa's Growth Tragedy: Policies and Ethnic Divisions," Quarterly Journal of Economics 111, 1203-1250.

Esteban, J. and D. Ray (1994) "On the Measurement of Polarization," Econometrica 62, 819-852.

Esteban, J. and D. Ray (1999) "Conflict and Distribution," Journal of Economic Theory 87, 379-415.

Esteban, J. and D. Ray (2007) "Polarization, Fractionalization and Conflict," Journal of Peace Research 45, 163-182.

Esteban, J. and D. Ray (2008) "On the Salience of Ethnic Conflict," American Economic Review 98, 2185-2202.

Esteban, J. and D. Ray (2011) "Linking Conflict to Inequality and Polarization," American Economic Review, forthcoming.

Fearon, J. (2003) "Ethnic and Cultural Diversity by Country," Journal of Economic Growth 8, 195-222.

Fearon, J. (2005) "Primary Commodity Exports and Civil War," Journal of Conflict Resolution 49, 483-507. 
Fearon, J., and D. Laitin (1999) "Weak States, Rough Terrain, and Large-Scale Ethnic Violence since 1945", Presented at the Annual Meetings of the American Political Science Association, Atlanta, GA.

Fearon, J., and D. Laitin (2000) "Violence and the Social Construction of Ethnic Identity," International Organization 54, 845-877.

Fearon, J. and D. Laitin (2003) "Ethnicity, Insurgency, and Civil War," American Political Science Review 97, 75-90.

Gleditsch, N-P., P. Wallensteen, M. Eriksson, M. Sollenber, and H. Strand (2002) "Armed Conflict 1946-2001: A New Dataset," Journal of Peace Research 39, 615-37.

Greenberg, J. (1956) "The Measurement of Linguistic Diversity," Language 32, 109-115.

Haber, S. and V. Menaldo (2011) "Do Natural Resources Fuel Authoritarianism? A Reappraisal of the Resource Curse," American Journal of Political Science 105, 1-26.

Hansen, B. (1996) "Inference when a nuisance parameter is not identified under the null hypothesis," Econometrica 64, 413-430.

Horowitz, D.L. (1985), Ethnic Groups in Conflict. Berkeley, CA: University of California Press.

King, G. and L. Zeng (2001), "Logistic Regression in Rare Events Data." Political Analysis 9, 137-163.

Laitin, D. (2000) "What is a Language Community?," American Journal of Political Science 44,142-155.

Lichbach, M. I. (1989) "An Evaluation of Does Economic Inequality Breed Political Conflict?," World Politics 4, 431- 470.

Maddison, A. (2008) "Historical Statistics of the World Economy: 1-2008 AD," http://www.ggdc.net/maddison/.

Midlarski, M.I. (1988), "Rulers and the Ruled: Patterned Inequality and the Onset of Mass Political Violence," American Political Science Review 82, 491-509.

Miguel, E., Satyanath, S. and E. Sergenti (2004) "Economic Shocks and Civil Conflict: An Instrumental Variables Approach," Journal of Political Economy 112, 725-753.

Montalvo, J. G. and M. Reynal-Querol (2005), "Ethnic Polarization, Potential Conflict and Civil War," American Economic Review 95, 796-816. 
Muller, E.N. and M.A. Seligson (1987) "Inequality and Insurgency," American Political Science Review 81, 425-451.

Muller, E. N., M.A. Seligson and H. Fu (1989) "Land inequality and political violence," American Political Science Review 83, 577-586.

Nagel, J. (1974), "Inequality and discontent: a non-linear hypothesis," World Politics 26, $453-472$.

Olson, M. (1971) The Logic of Collective Action. Cambridge MA: Harvard University Press.

Ray, D. (2009) "On the Initiation of Costly Conflict," mimeo., New York University. Reynal-Querol, M. (2002) "Ethnicity, Political Systems, and Civil Wars", Journal of Conflict Resolution 46, 29-54.

Ross, M. (2006), "A Closer Look at Oil, Diamonds and Civil War," Annual Review of Political Science 9, 265-300.

Rummel, R.J. (1963) "Dimensions of Conflict Behavior Within and Between Nations," General Systems Yearbook, VIII, 1-50.

Schneider, G.and N. Wiesehomeier (2006), "Ethnic Polarization, Potential Conflict, and Civil Wars: Comment," unpublished manuscript, University of Konstanz.

Sen, A. (1966) "Labour Allocation in a Cooperative Enterprise," Review of Economic Studies 33, 361-371.

Stram, D. O. and J. W. Lee. (1994), "Variance Components Testing in the Longitudinal Mixed Effects Model," Biometrics 50, 1171-1177.

Wolfson, M. C. (1994) "When Inequalities Diverge," American Economic Review Papers and Proceedings 84, 353-358.

\section{APPENDIX}

Definition of the Variables. We provide definitions of all major variables used in the paper. We begin with the different measures of conflict.

PRIO25. "Armed conflict" from PRIO: a contested incompatibility that concerns government and/or territory where the use of armed force between two parties, of which at least one is the government of a state, results in at least 25 battle-related deaths per year 
and per incompatibility. We consider only types 3 and 4 (internal armed conflict). If a country has experienced a PRIO25 conflict according to the PRIO dataset in any of the years of our five-year period, this variable takes a value equal to 1.

PRIOCW. "Intermediate armed conflict" from PRIO: includes all PRIO25 conflicts that result in a minimum of 1000 deaths over the course of the conflict. We consider only types 3 and 4 (internal armed conflict). If a country has experienced a PRIOCW conflict according to the PRIO dataset in any of the years of our five-year period, this variable takes a value equal to 1.

PRIO1000. "War" from PRIO: same definition as PRIO25 with a threshold of battlerelated deaths of at least 1000 per year and per incompatibility. We consider only types 3 and 4 (internal armed conflict). If a country has experienced a PRIO1000 conflict according to the PRIO dataset in any of the years of our five-year period, this variable takes a value equal to 1.

PRIOINT. "conflict intensity" from PRIO: we assign a value of 0 if there is peace in a given year, a value of 1 if there are events satisfying PRIO25 that are not PRIO1000, and a value of 2 if there are events recorded as PRIO1000. The value of PRIOINT is the maximum conflict level experienced within the five year period.

ISC. Index of social conflict. The Cross-National Time-Series Data Archive (CNTS) computes the ISC index as the weighted average of eight variables related to social unrest. ${ }^{49}$

Next, we define the three main distributional measures that we use.

\footnotetext{
${ }^{49}$ These variables are (weights are provided in brackets): Assassinations (domestic1) [25]: Any politically motivated murder or attempted murder of a high government official or politician. General Strikes (domestic2) [20]: Any strike of 1,000 or more industrial or service workers that involves more than one employer and that is aimed at national government policies or authority. Guerrilla Warfare (domestic3) [100]: Any armed activity, sabotage, or bombings carried on by independent bands of citizens or irregular forces and aimed at the overthrow of the present regime. Major Government Crises (domestic4) [20]: Any rapidly developing situation that threatens to bring the downfall of the present regime - excluding situations of revolt aimed at such overthrow. Purges (domestic5) [20]: Any systematic elimination by jailing or execution of political opposition within the ranks of the regime or the opposition. Riots (domestic6) [25]: Any violent demonstration or clash of more than 100 citizens involving the use of physical force. Revolutions (domestic7) [150]: Any illegal or forced change in the top government elite, any attempt at such a change, or any successful or unsuccessful armed rebellion whose aim is independence from the central government. Anti-government Demonstrations (domestic8) [10]: Any peaceful public gathering of at least 100 people for the primary purpose of displaying or voicing their opposition to government policies or authority, excluding demonstrations of a distinctly anti-foreign nature. The calculation of the ISC is performed as follows: weighted sum of occurrences of each event divided by the number of types of variables, 8 .
} 
$F$. Fractionalization, defined as $F=\sum_{i=1}^{m} n_{i}\left(1-n_{i}\right)$, where $n_{i}$ is the population share of group $i$ and $m$ is the number of groups. Data on group shares has been obtained from Fearon (2003) and the Ethnologue project (http://www.ethnologue.com).

$P$. Polarization, computed as $P=\sum_{i=1}^{m} \sum_{j=1}^{m} n_{i}^{2} n_{j} \kappa_{i j}$, where $\kappa_{i j}=1-s_{i j}^{0.05}$ and $s_{i j}$ is the degree of similarity between two languages $i$ and $j$, given by the ratio of the number of common branches to the maximum possible number - fifteen for the entire tree. ${ }^{50}$ Data on language trees has been obtained from Ethnologue.

$G$. Greenberg-Gini index, defined as $G=\sum_{i=1}^{m} \sum_{j=1}^{m} n_{i} n_{j} d_{i j}$. Same data sources as $P$.

$R$. Binary-distance polarization measure, defined as $R=\sum_{i=1}^{m} n_{i}^{2}\left(1-n_{i}\right)$. Same data sources as $F$.

Finally, we record the other variables and controls in alphabetical order.

A. Cohesion. Data from the 2005 wave of the World Value Survey has been used to construct $A$. For each individual, we compute the simple average of the scores to a set of questions related to group commitment and adhesion to social norms. ${ }^{51}$ The country estimate is the average of the individual averages.

AUTOCR. Institutionalized autocracy. Data source is POLITY IV and takes values on a 0-10 scale, with 10 signifying extreme autocracy. We transform this variable into a time-invariant dummy in the following way: first, the percentage of years in the sample for which a country received a score lower than 5 was calculated. Then, if this percentage was lower than $40 \%$, a country received a time-invariant 1 for this non-autocracy dummy and 0 otherwise.

CIVLIB. (Lack of) civil liberties. Data source is Freedom House, which considers a 1-7 scale (1 indicates highest level of liberties). We transform this variable into a timeinvariant dummy in the following way: first, the percentage of years in the sample for

\footnotetext{
$\overline{{ }^{50} \text { If two groups speak the same language, } s_{i j} \text { is set to } 1 .}$

${ }^{51}$ These questions are: V84: It is important to this person to help the people nearby; to care for their well-being. V87: It is important to this person to always behave properly; to avoid doing anything people would say is wrong. V89: Tradition is important to this person; to follow the customs handed down by one's religion or family. V7: For each of the following, indicate how important it is in your life. Would you say it is: Politics. V9: For each of the following, indicate how important it is in your life: Religion. V211: People have different views about themselves and how they relate to the world. Using this card, would you tell me how strongly you agree or disagree with each of the following statements about how you see yourself?: I see myself as part of my local community. All variables are normalized to a 1-4 scale.
} 
which a country received a score smaller than 4 was calculated. Then, if this percentage was smaller than $40 \%$, a country received a value of 1 in all the sample.

DEMOC. Institutionalized democracy. Data source is Polity IV, democracy ranges from 0 (low) to 10 (high). As in MRQ, DEMOC takes a value equal to 1 if the score is higher or equal to 4 and zero otherwise.

EXCONS. (Lack of) executive constraints. It is defined on a 1-7 scale (1 indicates minimum constraints); source is POLITY IV. We transform this variable into a timeinvariant dummy in the following way: first, the percentage of years in the sample for which a country received a score greater than 4 is computed. Then, if this percentage is smaller than 0.4, a country received a value of EXCONS equal to 1 in all the sample.

GDPPC. Log of real GDP per capita corresponding to the first year of each five-year period. Source: Maddison (2008).

Mount. Percent mountainous terrain. Data source is Fearon and Laitin (2003) who use the codings of geographer A.J. Gerard.

N. Population, in millions. Source: Maddison (2008).

NCONT. Noncontiguous states. Non contiguous state refers to countries with territory holding at least 10000 people and separated from the land area containing the capital city either by land or by 100 kilometers of water. Source: Fearon and Laitin (2003).

OIL/DIAM. Oil/Diamond dummy. It takes the value 1 if the country is "rich in oil" or produces (any positive quantity) of diamonds. A country is "rich in oil" if the average value of its oil production in a period is larger than 100 U.S dollars in 2000 constant dollars. Source: Ross (2006).

OILRESV. Per capita value of oil reserves at the beginning of the period. Data for oil reserves comes from Haber and Menaldo (2011). To convert quantities into dollars, we use the oil price data in Ross (2006), where prices are referred to the same year as reserves. Finally, we divide by population to obtain a per capita measure.

POLRIGHTS. (Lack of) political rights. Data source is Freedom House, which considers a 1-7 scale (1 indicates most free). We transform this variable into a time invariant dummy in the following way: first, the percentage of years in the sample for which a country 
received a score smaller than 4 was calculated. Then, if this percentage was smaller than $40 \%$, a country received a value of 1 in all the sample.

POP. Log of population in the first year of each five-year period. Source: Maddison (2008).

PUB. Publicness index. It is defined as the simple average of EXCONS, AUTOCR, POLRIGHTS and CIVLIB.

$\Lambda$. Relative publicness of the prize. It is defined as $\Lambda=\mathrm{PUB} /(\mathrm{PUB}+$ OILRESV/GDP).

The following table presents the mean and the standard deviation of all the variables employed in the empirical analysis. 


\begin{tabular}{lrr}
\hline Conflict Variables & mean & sd \\
\hline PRIO25 & .231 & .422 \\
PRIOCW & .156 & .363 \\
PRIO1000 & .090 & .286 \\
PRIOINT & .321 & .631 \\
ISC & 9.317 & 14.436 \\
\hline Ethnolinguistic Indices & mean & sd \\
\hline$P_{\delta=0.05}($ FEARON) & .0463 & .0542 \\
$G / N_{\delta=0.05}$ FEARON & .0442 & .129 \\
F (FEARON) & .417 & .245 \\
R (FEARON) & .123 & .063 \\
$P_{\delta=0.05}($ ETH $)$ & .043 & .048 \\
$G / N_{\delta=0.05}($ ETH $)$ & .110 & .365 \\
F $($ ETH $)$ & .451 & .319 \\
R (ETH) & .107 & .066 \\
\hline Other variables & mean & sd \\
\hline GDPPC & 7.985 & 1.111 \\
POP & 15.721 & 1.807 \\
MOUNT & 15.518 & 19.853 \\
NCONT & .146 & .353 \\
DEM & .472 & .499 \\
OIL/DIAM & .316 & .465 \\
OILRESV & 23960.4 & 170898.7 \\
PUB & .446 & .445 \\
EXCONS & .536 & .498 \\
AUTOCR & .371 & .483 \\
POLRIGHTS & .459 & .499 \\
CIVLIB & .475 & .500 \\
$\Lambda$ & .565 & .408 \\
A & .729 & .0728 \\
\hline
\end{tabular}

TABLE 10. Summary statistics. 